\title{
COPPER CATALYZED SODIUM TETRAPHENYLBORATE, TRIPHENYLBORANE, DIPHENYLBORINIC ACID AND PHENYLBORONIC ACID DECOMPOSITION KINETIC STUDIES IN AQUEOUS ALKALINE SOLUTIONS
}

by

C. L. Crawford, M. J. Barnes, R. A. Peterson, W. R. Wilmarth, M. L. Hyder

Westinghouse Savannah River Company

Savannah River Site

Aiken, SC 29808

A paper proposed for publication in the Journal of Organometallic Chemistry

The information contained in this article was developed during the course of work under Contract No. DE-AC09-96SR18500 with the U. S. Department of Energy. By acceptance of this paper, the publisher and/or recipient acknowledges the U. S. Government's right to retain a nonexclusive, royalty-free license in and to any copyright covering this paper along with the right to reproduce, and to authorize others to reproduce all or part of the copyrighted paper.

Westinghouse Savannah River Company Savannah River Technical Center Aiken, SC 29808

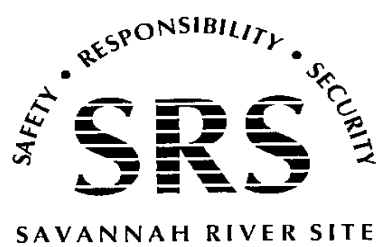




\title{
COPPER CATALYZED SODIUM TETRAPHENYLBORATE, TRIPHENYLBORANE, DIPHENYLBORINIC ACID AND PHENYLBORONIC ACID DECOMPOSITION KINETIC STUDIES IN AQUEOUS ALKALINE SOLUTIONS
}

\author{
by
}

C. L. Crawford, M. J. Barnes*, R. A. Peterson, W. R. Wilmarth, M. L. Hyder Westinghouse Savannah River Company, Savannah River Site Aiken, SC 29808

This document was prepared in conjunction with work accomplished under Contract No. DE-AC09-96SR18500 with the U. S. Department of Energy.

\section{DISCLAIMER}

This report was prepared as an account of work sponsored by an agency of the United States Government. Neither the United States Government nor any agency thereof, nor any of their employees, makes any warranty, express or implied, or assumes any legal liability or responsibility for the accuracy, completeness, or usefulness of any information, apparatus, product or process disclosed, or represents that its use would not infringe privately owned rights. Reference herein to any specific commercial product, process or service by trade name, trademark, manufacturer, or otherwise does not necessarily constitute or imply its endorsement, recommendation, or favoring by the United States Government or any agency thereof. The views and opinions of authors expressed herein do not necessarily state or reflect those of the United States Government or any agency thereof.

This report has been reproduced directly from the best available copy.

Available to DOE and DOE Contractors from the Office of Scientific and Technical Information, P. O. Box 62 Oak Ridge, TN 37831; prices available from (423) 576-8401. Available to the public from the National Technical Information Service, U.S. Department of Commerce, 5285 Port Royal Road, springfield, VA 22161.

\section{ABSTRACT}

This work studied the kinetics of copper-catalyzed decomposition of tetraphenylborate, triphenylborane, diphenylborinic acid and phenylboronic acid (NaTPB, 3PB, 2PB and 1PB, respectively) in aqueous alkaline solution over the temperature range of 25 to $70{ }^{\circ} \mathrm{C}$. The statistically designed test matrices added copper sulfate to maximum concentrations of $10 \mathrm{mg} / \mathrm{L}$. The relative rates of decomposition increase in the order of NaTPB $<1 \mathrm{~PB} \sim 3 \mathrm{~PB}<2 \mathrm{~PB}$. Dependence of decomposition on the amount of added copper increases in the order of $3 \mathrm{~PB} \sim 2 \mathrm{~PB}<1 \mathrm{~PB} \sim \mathrm{NaTPB}$. Activation energies ranged from 82 to 143 $\mathrm{kJ} /$ mole over the temperature range studied. Final decomposition products predominately involved benzene and phenol. All 3PB, 2PB and 1PB intermediate phenylborate species proved relatively stable $(<8 \%$ decomposition 
over $\sim 500 \mathrm{~h}$ ) towards thermal hydrolysis in $1.5 \mathrm{M} \mathrm{NaOH}$ when contained in carbon-steel vessels sealed under air at ambient temperature $\left(23-25^{\circ} \mathrm{C}\right)$ with no added copper. Measurable $\left(>10^{-7} \mathrm{Mh}^{-1}\right)$ thermal hydrolysis of the phenylborate species occurs at 55 to $70^{\circ} \mathrm{C}$ in alkaline $\left(0.6-2.3 \mathrm{M} \mathrm{OH}^{-}, 2-4.7 \mathrm{M}\right.$ $\mathrm{Na}^{+}$) solution with no added copper. The experiments suggest an important role for oxygen in copper-catalyzed phenylborate decomposition. NaTPB decomposes promptly under anoxic conditions while 3PB, 2PB and 1PB decompose faster in aerobic solutions. Benzene and phenol form as the predominant end-products from alkaline copper catalysis in static systems sealed under air. Both $2 \mathrm{~PB}$ and $1 \mathrm{~PB}$ decompose with near equal rates and quantitatively produce phenol under flowing air-purge conditions at 25 to $60^{\circ} \mathrm{C}$. Mechanisms for copper-catalyzed phenylborate decomposition likely involve a redox process giving loss of a phenyl group from the phenylborate with reduction of cupric ion, or dephenylation by reduced cuprous ion involving a phenylated copper intermediate.

Keywords: Copper-catalyzed decomposition; Sodium tetraphenylborate; Triphenylborane; Diphenylborinic acid; Phenylboronic acid; Kinetics

* Corresponding author: Westinghouse Savannah River Company, Building 773-A, Savannah River Site, Aiken, SC 29808

E-mail: mark.barnes@srs.gov, Fax: (803) 725-4704 


\section{INTRODUCTION}

The In-Tank Precipitation facility at the Savannah River Site prepares high-level radioactive waste for vitrification in the Defense Waste Processing Facility [1-3]. The process uses sodium tetraphenylborate (NaTPB) to precipitate cesium and potassium in strongly alkaline aqueous media [4]. During commissioning of the process in 1995, all excess NaTPB unexpectedly decomposed $[5,6]$. The literature indicates that NaTPB solutions hydrolyze unless stabilized by sodium hydroxide [7]. Previous experience with aqueous NaTPB solutions indicated that even in the presence of sodium hydroxide, NaTPB decomposes in the presence of soluble copper [8]. The previous investigation focused on determination of components such as copper, temperature and solution $\mathrm{pH}$ that could influence NaTPB stability [8]. However, this previous study did not attempt to develop kinetic expressions for NaTPB decomposition [8]. The present study develops a more complete understanding of the kinetics of copper-catalyzed NaTPB decomposition for subsequent comparison to facility measurements.

Postulated mechanisms for the decomposition of soluble tetraphenylborate ion (TPB-) include a sequential loss of phenyl groups from the tetraphenylborate ( $\left.\mathrm{TPB}^{-}\right)$through triphenylborane (3PB or $\left.\left(\mathrm{C}_{6} \mathrm{H}_{5}\right)_{3} \mathrm{~B}\right)$, diphenylborinic acid (2PB or $\left.\left(\mathrm{C}_{6} \mathrm{H}_{5}\right)_{2} \mathrm{BOH}\right)$ and phenylboronic acid (1PB or $\left.\mathrm{C}_{6} \mathrm{H}_{5} \mathrm{~B}(\mathrm{OH})_{2}\right)$, ultimately leading to the stable phenol, benzene and boric acid. Modeling the overall decomposition scheme requires an understanding of each reaction step. This report describes our preliminary kinetic investigations to determine reaction rates and decomposition products of NaTPB, 3PB, 2PB and 1PB in aqueous alkaline solution in the presence of soluble copper ion between 25 and $70^{\circ} \mathrm{C}$.

\section{Phenylborate Decomposition: Hydrolysis and Reactions Involving Copper}

Previous work examined tetraphenylborate instability under acidic conditions $[9,10]$. The Savannah River Site proposes acidic, copper-catalyzed decomposition of tetraphenylborate slurries as the reference process for destroying CsTPB precipitates [11,12]. This process, using a formic/nitric acid mixture at boiling temperatures of 100 to $102{ }^{\circ} \mathrm{C}$, nominally converts the tetraphenylborate molecule to $90.4 \%$ benzene, $4.9 \%$ biphenyl and $3.4 \%$ diphenylamine [11]. The volatile organic compounds separate from the reaction mixture. The process subsequently blends the resulting waste slurry, containing radioactive cesium and less than 10 percent of the original organic compounds, with high level radioactive sludge and transfers the mixture to a vitrification facility for processing into borosilicate glass for long-term storage. Other studies investigated tetraphenylborate decomposition using chemical oxidation [13-15], photolytic [16-18], electrochemical [19-21] and radiolytic processes [22-25]. Decomposition products identified in these studies include diphenylborinic acid, phenylboronic acid, biphenyl, benzene and phenol. 
Copper reacts with or influences the chemistry of the tetraphenylborate ion [2628]. Wittig and Raff observed cleavage of the tetraphenylborate to trisubstituted boron compounds (triphenylborane and diphenylborinic acid) and biphenyl in ethyl ether solvent. These studies also produced an impure solid cuprous tetraphenylborate solid, $\mathrm{Cu}^{\prime} \mathrm{BPh}_{4}$. Other researchers observed decomposition of this solid when exposed to air [27] and when allowed to react with carbonyl compounds [28]. Costa et al. report that all the phenyl groups of $\mathrm{Cu}^{\prime} \mathrm{BPh}_{4}$ easily hydrolyze in moist solvents [29]. Costa also reported preparation of solid $\mathrm{Cu}^{\prime} \mathrm{BPh}_{4}$ from reaction of the sigma-bonded phenylcopper compound, $\mathrm{CuC}_{6} \mathrm{H}_{5}$, with triphenylborane [30].

Triphenylborane hydrolyzes rapidly in dilute alkaline solution [31]. In strongly alkaline solution, triphenylborane exists as the stable sodium hydroxide adduct hydroxytriphenylborate, $\left[\mathrm{Na}^{+}\left(\mathrm{C}_{6} \mathrm{H}_{5}\right)_{3} \mathrm{BOH}^{-}\right]$. Brown and Dodson observed decomposition of 3PB over an 8 hour period when kept in contact with distilled water. In contrast, both Sidgwick [32] and Simon [10] report 3PB as inert towards hydrolysis. These reported differences in neutral aqueous 3PB stability could depend on the presence of oxygen. Simon asserts that dissolved oxygen present in neutral aqueous 3PB solutions promotes hydrolysis reactions. Simon did not observe 3PB decomposition when rigorously excluding oxygen from aqueous solution.

Anodic oxidation of a variety of triarylborons including 3PB has been investigated in acetonitrile solution [33,34]. Anodic oxidation of 3PB proved irreversible and allegedly involves generation of the radical cation, $\left(\mathrm{C}_{6} \mathrm{H}_{5}\right)_{3} \mathrm{~B}^{+}$, that decomposes giving $\left(\mathrm{C}_{6} \mathrm{H}_{5}\right)_{2} \mathrm{~B}^{+}$and $\mathrm{C}_{6} \mathrm{H}_{5}{ }^{\circ}$. To our knowledge, the only published studies of copper catalyzed 3PB destruction derive from the patented precipitate hydrolysis process at the Savannah River Site [11]. The mechanistic scheme involves initial formic acid attack of the parent NaTPB, producing formate ion, triphenylborane and benzene. Cupric ion then presumably catalyzes the destruction of tri-, di- and monophenylborate species in aqueous solution, ultimately leading to predominately benzene.

Tricoordinate phenylboronic acid and diphenylborinic acid are converted to their respective tetracoordinate hydroxy anions in basic media [35,36]. The pKa for $1 \mathrm{~PB}$ at $25^{\circ} \mathrm{C}$ is 8.70 [35]. Hatt showed phenylboronic acid as stable towards hydrolysis in the range of $50-100^{\circ} \mathrm{C}$ only at $\mathrm{pH} 13$ [37]. Phenylboronic acid underwent extensive hydrolysis at lower $\mathrm{pH}$ 's in this temperature range. These results agree with the observations of Ainley and Challenger who found that phenylboronic acid appears unchanged after $20 \mathrm{~h}$ boiling with $5 \mathrm{wt} \%$ aqueous sodium hydroxide [38]. Kuivila and coworkers published a series of investigations on both the protodeboronation [39] and metal ion catalysis protodeboronation [40] of phenylboronic acid (i.e., an 'areneboronic acid'). General acid catalysis has been postulated for these reactions. The metals, including copper(II), allegedly act as dephenylating agents to form easily oxidized organometallic intermediates that react with water to form benzene. 
Decomposition Reactions for Oxidation and Hydrolysis

Generalized alkaline hydrolysis reactions of the phenylborates in the presence of copper can be represented by,

$$
\begin{aligned}
& \mathrm{B}\left(\mathrm{C}_{6} \mathrm{H}_{5}\right)_{\mathrm{x}=4,3,2,1}(\mathrm{OH})^{-} \mathrm{y}=0,1,2,3+\mathrm{H}_{2} \mathrm{O}-\left(\mathrm{Cu}^{\mathrm{n}+}\right) \rightarrow \\
& \mathrm{B}\left(\mathrm{C}_{6} \mathrm{H}_{5}\right)_{x^{\prime}=3,2,1,0}(\mathrm{OH})^{-} y^{\prime}=1,2,3,4+\mathrm{C}_{6} \mathrm{H}_{6} \\
& \mathrm{~B}\left(\mathrm{C}_{6} \mathrm{H}_{5}\right)_{x=4,3,2,1}(\mathrm{OH})^{-} \mathrm{y}=0,1,2,3+\mathrm{H}_{2} \mathrm{O}+1 / 2 \mathrm{O}_{2}-\left(\mathrm{Cu}^{\mathrm{n}+}\right) \rightarrow \\
& \mathrm{B}\left(\mathrm{C}_{6} \mathrm{H}_{5}\right)_{x^{\prime}=3,2,1,0}(\mathrm{OH})^{-} \mathrm{y}^{\prime}=1,2,3,4+\mathrm{C}_{6} \mathrm{H}_{5} \mathrm{OH}
\end{aligned}
$$

Reactions 1 and 2 indicate possible alkaline hydrolysis for all the phenylborate species $\mathrm{B}\left(\mathrm{C}_{6} \mathrm{H}_{5}\right)_{4}{ }^{-}, \mathrm{B}\left(\mathrm{C}_{6} \mathrm{H}_{5}\right)_{3}(\mathrm{OH})^{-}, \mathrm{B}\left(\mathrm{C}_{6} \mathrm{H}_{5}\right)_{2}(\mathrm{OH})_{2}{ }^{-}$, and $\mathrm{B}\left(\mathrm{C}_{6} \mathrm{H}_{5}\right)(\mathrm{OH})_{3}{ }^{-}$. These reactions assume soluble copper of unspecified valence state. The expressions suggest that hydrolysis in absence of oxygen leads to predominately benzene, whereas incorporation of oxygen into the hydrolysis steps leads to phenol. Specific oxidation reactions of the phenylborates in alkaline solution in the presence of copper can occur as,

$$
\begin{aligned}
& \mathrm{B}\left(\mathrm{C}_{6} \mathrm{H}_{5}\right) 4^{-}+2 \mathrm{Cu}(\mathrm{OH}) 4^{2-} \rightarrow \\
& 2 \mathrm{Cu}(\mathrm{OH}) 2^{-}+\mathrm{B}\left(\mathrm{C}_{6} \mathrm{H}_{5}\right) 2(\mathrm{OH}) 2^{-}+\left(\mathrm{C}_{6} \mathrm{H}_{5}\right) 2+2 \mathrm{OH}^{-} \\
& \mathrm{B}\left(\mathrm{C}_{6} \mathrm{H}_{5}\right)_{\mathrm{x}=4,3,2,1}(\mathrm{OH})^{-} \mathrm{y}=0,1,2,3+2 \mathrm{Cu}(\mathrm{OH}) 4^{2-} \rightarrow \\
& 2 \mathrm{Cu}(\mathrm{OH}) 2^{-}+\mathrm{B}\left(\mathrm{C}_{6} \mathrm{H}_{5}\right)_{x^{\prime}=3,2,1,0}(\mathrm{OH})^{-} \mathrm{y}^{\prime}=1,2,3,4 \\
&
\end{aligned}
$$

The products from these reactions include biphenyl or the phenylate anion, $\mathrm{C}_{6} \mathrm{H}_{5} \mathrm{O}^{-}$. The dihydroxy cuprate (I) anion formed in reactions 3 and 4 could undergo oxidation to form the tetrahydroxy complex in the presence of oxygen.

$$
4 \mathrm{Cu}(\mathrm{OH})_{2}^{-}+4 \mathrm{OH}^{-}+2 \mathrm{H}_{2} \mathrm{O}+\mathrm{O}_{2} \rightarrow 4 \mathrm{Cu}(\mathrm{OH}) 4^{2-}
$$

The reduced form of cuprate ion, $\mathrm{Cu}(\mathrm{OH}) 2^{-}$, can also be postulated to serve as a catalyst to promote 'dephenylation' of the phenylborates as shown in Reactions 6-7 below, primarily leading to benzene. Reaction 7 resembles that suggested by Kuivila et al. for arylmetal(I) halides undergoing hydrolysis to produce benzene and the corresponding metal(II)halide hydroxide [40].

$$
\begin{array}{rl}
\mathrm{B}\left(\mathrm{C}_{6} \mathrm{H}_{5}\right)_{\mathrm{x}=4,3,2,1}(\mathrm{OH})^{-} \mathrm{y}=0,1,2,3 & \mathrm{Cu}(\mathrm{OH}) 2^{-} \rightarrow \\
& \mathrm{B}\left(\mathrm{C}_{6} \mathrm{H}_{5}\right)_{x^{\prime}=3,2,1,0}(\mathrm{OH})^{-} \mathrm{y}^{\prime}=1,2,3,4 \\
\end{array}
$$


Several authors report decomposition schemes involving oxidation of tetraphenylborate by chemical [13-15], photolytic [16-18], electrolytic [19-21], and radiolytic [22-25] techniques to produce the tetraphenylboron radical. All of these studies show predominately both biphenyl and diphenylborinic acid as products. Reactions 8 through 12 provide a generalized scheme for the oxidation reaction followed by various free radical decay steps.

$$
\begin{aligned}
& \mathrm{B}\left(\mathrm{C}_{6} \mathrm{H}_{5}\right) 4^{-}+[\mathrm{Ox}] \rightarrow \mathrm{B}\left(\mathrm{C}_{6} \mathrm{H}_{5}\right) 4^{\circ}+[\mathrm{Ox}]^{-} \\
& \mathrm{B}\left(\mathrm{C}_{6} \mathrm{H}_{5}\right)_{4} \rightarrow \mathrm{B}\left(\mathrm{C}_{6} \mathrm{H}_{5}\right)_{2}{ }^{\circ}+\left(\mathrm{C}_{6} \mathrm{H}_{5}\right)_{2} \\
& \mathrm{~B}\left(\mathrm{C}_{6} \mathrm{H}_{5}\right)_{4} \cdot \rightarrow \mathrm{B}\left(\mathrm{C}_{6} \mathrm{H}_{5}\right)_{3}+\left(\mathrm{C}_{6} \mathrm{H}_{5}\right)^{\bullet} \\
& \mathrm{B}\left(\mathrm{C}_{6} \mathrm{H}_{5}\right) 4^{\cdot}+[\mathrm{Ox}] \rightarrow \mathrm{B}\left(\mathrm{C}_{6} \mathrm{H}_{5}\right)_{2}{ }^{+}+\left(\mathrm{C}_{6} \mathrm{H}_{5}\right)_{2}+[\mathrm{Ox}]^{-} \\
& \mathrm{B}\left(\mathrm{C}_{6} \mathrm{H}_{5}\right)_{2}{ }^{+}+2 \mathrm{H}_{2} \mathrm{O} \rightarrow\left(\mathrm{C}_{6} \mathrm{H}_{5}\right)_{2} \mathrm{BOH}+\mathrm{H}_{3} \mathrm{O}^{+}
\end{aligned}
$$

We observed near exclusive production of either benzene or phenol in recent tetraphenylborate decompositions under plant processing conditions $[5,6]$ and in the present controlled laboratory tests with copper catalyzed phenylborate decomposition in aqueous solution. Thus our focus on the generalized decay scheme above largely ignores production of biphenyl (i.e., reaction 3).

\section{EXPERIMENTAL}

The studies used ACS reagent grade NaTPB (99.5+\%), triphenylborane (6 wt \% $\mathrm{NaOH}$ adduct in water), diphenylborinic acid as the ethanolamine ester (98\%) and phenylboronic acid (97\%) from Aldrich Chemical Company. Reagent-grade sodium hydroxide came from Spectrum Quality Products, Inc. Reagent-grade copper nitrate hexahydrate, $\left.\mathrm{Cu}\left(\mathrm{N}_{3}\right)_{2}\right)^{-6} \mathrm{H}_{2} \mathrm{O}$ or copper sulfate pentahydrate, $\mathrm{CuSO}_{4} \cdot 5 \mathrm{H}_{2} \mathrm{O}$ from Fisher Scientific served as copper sources for these studies. All solutions used distilled, deionized water $\left(\sim 18 \mathrm{M} \Omega \bullet \mathrm{cm}\right.$ resistivity at $\left.25^{\circ} \mathrm{C}\right)$. Experimental details varied in these studies investigating copper catalysis of NaTPB, 3PB, 2PB and 1PB. Descriptions of the various methodologies follow.

\section{Sodium Tetraphenylborate Decomposition Tests}

Laboratory tests of NaTPB decomposition used 200-mL glass vessels continuously ventilated and magnetically stirred. Glass vessels were fitted with stopcocks and septa made of inert material to allow periodic sampling by gas chromatographic syringes. The tests used $100 \mathrm{~mL}$ of each test solution prepared from stock solutions of NaTPB, sodium hydroxide, and copper(II) nitrate followed by dilution with distilled deionized water. Each test solution contained $10 \mathrm{mg} / \mathrm{L}$ of total copper. Either humidified air or nitrogen passed through the vapor space of the reaction vessel at a flow rate of approximately 
$10 \mathrm{~mL} / \mathrm{min}$. A $5 \mathrm{vol} \%$ oxygen-in-nitrogen mixture passed through the reaction vessel for one pair of tests. Liquid samples obtained periodically were analyzed for tetraphenylborate ion (TPB-) by either silver titration or High Performance Liquid Chromatography (HPLC) to determine the extent of reaction.

The software package JMP ${ }^{\circledR}$, from SAS Institute, Inc., was used to examine candidate statistical designs appropriate for this study [41]. The selected design (See Table 1) examined primary effects associated with four controlled parameters: tetraphenylborate concentration, hydroxide concentration, temperature, and reaction atmosphere [42]. Note that in Tests 7 and 8, it is impossible, owing to solubility limitations, to have both a high tetraphenylborate concentration and a high hydroxide concentration. For this reason, these experiments lowered the concentrations of each component to accommodate the solubility limit for the tetraphenylborate while maintaining both species at relatively high values. The copper content was kept constant for the tests. However, the soluble copper concentration varied with the temperature and hydroxide concentration of each test.

Triphenylborane, Diphenylborinic Acid, and Phenylboronic Acid Decomposition $\underline{\text { Studies }}$

The copper-catalyzed kinetics of 3PB, 2PB and 1PB were studied under identical reaction conditions in $160-\mathrm{mL}$ carbon steel vessels sealed under air. Carbon steel vessels were fitted with Swage-lok ${ }^{\circledR}$ fittings and septa made of inert material to allow periodic sampling by gas chromatographic syringes. Teflon ${ }^{\circledR}$ gaskets sealed the caps to the vessels. Caps were tightened in place via three equally spaced threaded bolts permanently attached (welded) to the vessel outer surfaces. Carbon steel vessels were cleaned before each test by use of a dilute $1 \% \mathrm{HNO}_{3} 1 \mathrm{~h}$ acid soak, deionized water rinse, $\sim 8 \mathrm{~h}$ annealing period, an overnight soak in nominally $1 \mathrm{M} \mathrm{NaOH}$ solution, followed by final deionized water rinse. Ten experiments examined each of the 3PB, 2PB and $1 \mathrm{~PB}$ organic components. These tests used a statistically designed matrix generated by the statistical program JMP [41]. Table 2 shows the blocked, facecentered central composite design selected [42]. The tests investigated the main effects of the four parameters: temperature, organic, hydroxide and copper concentrations. The two center points provide a check for curvilinear response over the range studied. The duplicate tests also provide indication of the precision or repeatability of our data under current test conditions.

Chemical analyses for the 3PB, 2PB and 1PB alkaline aqueous systems allow one to determine the rates of reaction and significant product yields in the presence of copper at various temperatures. The computer program JMP provided detailed analysis of each data set [41]. Rate expressions derived from the initial decay slopes of the concentration versus time plots for each organic component provide relative decomposition comparisons for the three organic components under identical reaction conditions. 


\section{Flowing Air Studies with Diphenylborinic Acid and Phenylboronic Acid}

These tests dissolved reagent-grade sodium hydroxide in distilled, deionized water to provide a $1.5 \mathrm{M}$ stock solution. To this stock solution, diphenylborinic acid (as the solid ethanolamine ester) and phenylboronic acid (as the pure solid) were added. The mixtures contained phenylborate intermediates at a starting concentration of approximately $2000 \mathrm{mg} / \mathrm{L}(\sim 0.01 \mathrm{M})$. Intermediates were added to the sodium hydroxide solution at room temperature in polyethylene bottles and allowed to dissolve for one day prior to starting the decomposition tests. After one day, an 1/3 mL solution of copper nitrate hexahydrate, $\mathrm{Cu}\left(\mathrm{N}_{3}\right) 2 \cdot 6 \mathrm{H}_{2} \mathrm{O}$, in distilled, deionized water was added to glass reaction vessels via a $5-\mathrm{mL}$ glass syringe to give a concentration of $10 \mathrm{mg} / \mathrm{L}$. Then approximately $100 \mathrm{~mL}$ of phenylborate intermediate in aqueous solution was added to the reaction vessel using a $5-\mathrm{mL}$ glass syringe. Glass vessels used in these experiments included a coarse glass frit attached to the end of the glass air purge tube submersed into the solution. The glass tubes were attached to an air purge and the vessels were placed in pre-heated water baths at temperatures of $25^{\circ} \mathrm{C}$ and $40^{\circ} \mathrm{C}$. Air -- pre-saturated with alkali by sparging through $1.5 \mathrm{M}$ $\mathrm{NaOH}$-- flowed at a sufficient rate of $\sim 10 \mathrm{cc} / \mathrm{min}$ to provide a continuous stream of bubbles. Tests occurred in duplicate.

\section{$\underline{\text { Analyses }}$}

All samples were filtered using a 0.45 micron filter prior to analysis by HPLC. Two different HPLC methods were employed. One HPLC method used a TSP LC instrument with acetonitrile-ammonium phosphate buffer eluent and a Whatman Partisil 10 ODS-2 $4.6 \times 250 \mathrm{~mm}$ column to separate and quantify NaTPB, 3PB and 2PB. The other HPLC method used a Hewlett Packard LC instrument with acetonitrile-water eluent and a Chemosorb-5-ODS-UH $4.6 \times 250$ $\mathrm{mm}$ column to separate and quantify $1 \mathrm{~PB}$ and phenol. Further details concerning analyses of these organoborane compounds and phenol by HPLC methods have recently been described by Hsu and White [43].

Benzene measurements used a HNU, Inc., Model 301 gas chromatograph (GC) fitted with a $10.2 \mathrm{eV}$ photoionization detector and a $1 / 8$ in $\times 3 \mathrm{ft}$ packed column of $3 \%$ SP-2100 on $100 / 120$ mesh Supelcoport at $55^{\circ} \mathrm{C}$. The GC instrument was calibrated for benzene with gravimetrically prepared standards from ACS reagent grade benzene supplied by Aldrich Chemical Company.

Limited exploratory tests examined copper catalysis of the phenylborates with in situ solution phase oxygen monitoring. The in situ solution measurements used a Model 58 oxygen meter and Model 5739 probe (YSI, Inc., Yellow Springs, OH). The probe consists of a small electrochemical cell enclosed in a cylindrical plastic housing. The cell contains $\mathrm{KCl}$ solution as electrolyte separated from surrounding air or liquids by a oxygen permeable fluorocarbon membrane of 1 $\mathrm{cm}$ diameter. Rigid exclusion of air in-leakage in these tests resulted from use of 
glass vessels fitted with stopcocks. Nitrogen flow was used to transfer from the reaction vessel through plastic lines to a special measurement cell where the solutions were analyzed for oxygen content. For reliable measurements, oxygen analysis typically used a magnetic stirrer to equilibrate the probe with the solution in less than one minute.

\section{RESULTS AND DISCUSSION}

\section{Thermal Hydrolysis of Phenylborates}

Our studies initially examined the stability of the phenylborate species toward non-catalytic thermal hydrolysis. These limited tests only provide approximate decay rates for comparison to copper catalyzed decomposition rates discussed later in this report. Table 3 gives the results of these thermal hydrolysis tests in alkaline solutions in the absence of copper. The first-order decay rate constants assumed the overall storage time intervals shown. All reactions occurred under static conditions using vessels sealed under air. The results at ambient temperature indicate the relative long-term (i.e., $500 \mathrm{~h}$ or longer) stability of 3PB, $2 \mathrm{~PB}$ and $1 \mathrm{~PB}$ under conditions tested. Decomposition of $2 \mathrm{~PB}$ and $1 \mathrm{~PB}$ proved essentially undetectable (i.e., less than $2 \%$ total decomposition) within the limit of HPLC analysis. Results for 3PB indicate only slight $\sim 8 \%$ decomposition over $500 \mathrm{~h}$. Tests at 55 to $70^{\circ} \mathrm{C}$ showed NaTPB to be the most stable under conditions tested. The $70^{\circ} \mathrm{C}$ data shows that under these conditions $2 \mathrm{~PB}$ and 1PB decompose approximately twice as fast as NaTPB. (We lacked analytical HPLC procedures for $3 \mathrm{~PB}$ during these initial tests at 55 to $70^{\circ} \mathrm{C}$.)

\section{$\underline{\text { Rate Expressions }}$}

Inspection of the experimental data indicates that significant decomposition of each phenylborate species occurs under the present test conditions in the presence of copper. The data were analyzed using expressions of the form:

$$
\begin{aligned}
& \frac{d\left\lfloor X_{S}\right\rfloor}{d t}=-k\left[X_{S}\right]^{a}\left[\mathrm{Cu}^{n+}\right]^{b}\left[\mathrm{OH}^{-}\right]^{c} \\
& \text { with: } \quad k=A \mathrm{e}^{\left(-\mathrm{E}_{\mathrm{a}} / \mathrm{RT}\right)}
\end{aligned}
$$

where: $\quad\left[x_{S}\right]=$ the molar concentration of the species of interest $\left[\mathrm{Cu}^{\mathrm{n}+}\right]=$ the molar concentration of copper

(Note: $\mathrm{Cu}^{\mathrm{n}+}=$ soluble copper of unknown oxidation state)

$\left[\mathrm{OH}^{-}\right]=$the hydroxide ion molar concentration

$a, b, c=$ order of reaction for each respective component

$\mathrm{k}=$ rate constant 


$$
\begin{aligned}
& A=\text { pre-exponential factor } \\
& E_{\mathrm{a}}=\text { activation energy } \\
& \mathrm{R}=\text { gas constant }\left(8.314 \mathrm{JK}^{-1} \text { mole }^{-1}\right) \\
& \mathrm{T}=\text { temperature }(\mathrm{K})
\end{aligned}
$$

The rates were assumed to vary linearly with the concentration of the organic species. This assumption proves consistent with the rate expressions derived. Therefore, holding the copper concentration, hydroxide concentration and temperature constant throughout an experiment, equation 13 is integrated to produce:

$$
\frac{\left[X_{S}\right]}{\left[X_{S}\right]_{0}}=e^{-k\left[\mathrm{Cu}^{n+}\right]^{b}\left[\mathrm{OH}^{-}\right]^{c} t}
$$

Evaluation of this expression with respect to the experimental data yields estimates of the rate expression parameters for each of the phenylborate compounds. The following text discusses each of these expressions.

\section{Sodium Tetraphenylborate Decomposition}

The present experiments varied four parameters: NaTPB concentration, sodium hydroxide concentration, temperature, and oxygen concentration. Table 4 contains the rate of NaTPB reaction determined for each test. Least squares analysis was used on those tests (i.e., 1 - 4, 7, 9, and 10) with slow, nearly linear, rates of decomposition. In the remaining tests (i.e., 5, 6, 8, 11, and 12), the estimated rate of loss of NaTPB comes from a linear fit of the portion of the most reactive time period. An indication of the reproducibility of these decomposition tests is obtained by considering the measured rates from both duplicate test sets of tests 6 and 12 and of tests 9 and 10 shown in Table 4 . Tests 6 and 12 indicate an average decomposition rate of $6.9 \pm 0.71 \times 10^{-3} \mathrm{Mh}^{-1}$. Tests 9 and 10 indicate an average decomposition rate of $7.7 \pm 0.14 \times 10^{-6} \mathrm{Mh}^{-1}$. Thus the relative standard deviation for these two duplicate test sets is in the range of $2-10 \%$. Errors $( \pm)$ cited above and elsewhere within this document when applied to experimental measurements refer to the 1-sigma standard deviation for results from multiple tests.

The statistical analysis allows the main effects of the four factors on the TPBrate of decomposition to be determined. The initial NaTPB molar concentration appears significant at the $95 \%$ confidence level. The temperature is also significant at the $95 \%$ confidence level, but there is an indication of a lack of fit for this model. The other two factors, hydroxide concentration and percentage oxygen, appear insignificant. Plotting the data from Table 4 as an Arrhenius line in Figure 1, the activation energy for the reaction catalyzed by the total amount of copper is calculated to be $(143 \pm 35) \mathrm{kJ} / \mathrm{mole}$. The data, however, include 
considerable scatter as shown in Figure 1. This scatter suggests another unknown effect (e.g., a secondary interaction) involved in the reaction. Analysis of previous NaTPB decomposition data [8] and the current NaTPB decomposition tests leads to the following kinetic rate expression that best approximates the copper catalyzed decomposition of NaTPB as shown in equation 16.

$$
\frac{d[N a T P B]}{d t}=-1.1 \times 10^{23} e^{\frac{-143,030}{\mathrm{RT}}}\left[C u^{n+}\right][N a T P B]
$$

Inspection of equation 16 shows an unusually large pre-exponential factor and a larger than typical activation energy of $143 \mathrm{~kJ} / \mathrm{mole}$ versus more common values of $50-100 \mathrm{~kJ} / \mathrm{mole}$. Thus equation 16 probably does not correspond to a theoretical expectation for any simple mechanism. The kinetic expression more probably corresponds to several steps rather than one mechanistic step in a complex sequence.

Influence of Oxygen on the Initiation of Sodium Tetraphenylborate Decomposition

Tests 11 and 12 show the influence of oxygen on the decomposition of NaTPB. These tests were identical except for the ventilation gas. Figure 2 (airventilated) and Figure 3 (nitrogen-ventilated) show data from these tests. At the time of these initial NaTPB decomposition tests, we had not developed capability for measuring either 3PB or 2PB. These two components are thus not shown in Figures 2 and 3. Data plotted in Figures 2 and 3 indicate that two distinct reaction mechanisms involved in the decomposition process. In air (Test 11 shown in Figure 2), an induction period of nearly $100 \mathrm{~h}$ occurred. After the reaction initiated, a benzene generation rate in excess of $2,000,000 \mu \mathrm{g} / \mathrm{L} / \mathrm{h}$ resulted. In the nitrogen ventilated test (Test 12 shown in Figure 3), no induction period occurred. Reaction appeared almost instantaneous and the benzene generation rate reached at least $1,800,000 \mu \mathrm{g} / \mathrm{L} / \mathrm{h}$. The reaction stoichiometry also differed for the two tests. Only trace amounts $(<0.3$ mole \%) of phenol formed in the nitrogen ventilated test, with benzene as the primary product $(99.7$ mole \%). This contrasts the air-ventilated test in which 9.6 mole \% phenol formed with 90.4 mole \% benzene.

We propose that a relatively slow reaction occurred in the air-ventilated test to consume dissolved oxygen initially in solution over the initial $100 \mathrm{~h}$ to produce the $\sim 10 \%$ phenol. Initiation of rapid benzene production in this test likely indicates the occurrence of reactions 6 and 7 . This interpretation suggests that, under our test conditions, oxygen supplied by the air-ventilation at $\sim 10 \mathrm{cc} / \mathrm{min}$ eventually did not sufficiently maintain concentrations in the solution phase (as dissolved oxygen) to adequately promote reaction 5 and thus maintain copper as the oxidized (and proposed less reactive) cupric ion. 
Experiments with sealed vessels under static conditions using in situ dissolved oxygen monitoring confirmed that aerated $\mathrm{NaTPB}$ alkaline $1 \mathrm{M} \mathrm{NaOH}$ solutions remain relatively nonreactive for $300 \mathrm{~h}$ at $60^{\circ} \mathrm{C}$ in the presence of $10 \mathrm{mg} / \mathrm{L}$ copper. Figure 4 shows data from a typical experiment designed to monitor dissolved oxygen. Dissolved oxygen in these tests disappeared over the initial 300 hours. The initial saturated oxygen level steadily decreased as a function of time until complete depletion. After total consumption of dissolved oxygen, significant NaTPB decomposition occurred after $300 \mathrm{~h}$ at $60^{\circ} \mathrm{C}$. Figure 4 also shows the appearance of 3PB, 2PB, 1PB and phenol concurrent with NaTPB decomposition. Consumption of oxygen in these tests likely results from either a very slow reaction involving NaTPB or possibly an impurity associated with NaTPB. A similar test used initial deaeration of the solution by nitrogen purging. Figure 5 shows data from the deaerated solution and indicates that significant NaTPB decomposition promptly occurred in the initial 100 hours. The decomposition products 3PB, 2PB, 1PB and phenol appeared in solution as NaTPB promptly decayed.

The results discussed above pertaining to the influence of oxygen on NaTPB decomposition provide insight into the proposed mechanisms described by either reactions 4-5 or reactions 6-7 presented earlier. We observe relatively insignificant decomposition of NaTPB in the presence of dissolved oxygen. This observation, in conjunction with observation of prompt NaTPB decomposition in anoxic solution, suggests that reactions 6 and 7 occur much faster than reaction 4. In the presence of oxygen, reaction 5 appears to effectively compete with reactions 6 and 7 allowing copper ion to remain as the oxidized cupric ion.

\section{$\underline{\text { Triphenylborane Decomposition }}$}

Table 5 contains decomposition rate data for each 3PB test in vessels sealed under air. Our analysis of the data in Table 5 for decomposition of 3PB in vessels sealed under air shows that hydroxide plays no statistically significant role in the reaction. However, the decomposition shows an approximate 1/3order dependence on total copper concentration. Equation 17 represents the rate expression for the best fit of the experimental data. Indication of the reproducibility of this decomposition test set is obtained by considering the measured rates from duplicate tests 9 and 10 of Table 5 . Tests 9 and 10 indicate an average decomposition rate of $2.1 \pm 0.78 \times 10^{-6} \mathrm{Mh}^{-1}$. Thus the relative standard deviation for these two duplicate test sets is only about $38 \%$. This precision calculated for the 3PB test set is not as good as the precision found for the 2PB and 1 PB test sets discussed below.

$$
\frac{d[3 P B]}{d t}=-1.7 \times 10^{12} e^{\frac{-82,200}{\mathrm{RT}}}\left[C u^{n+}\right]^{0.4}[3 P B]
$$

Figure $6(\mathrm{~A}-\mathrm{C})$ show comparison of the measured 3PB decay versus the predicted 3PB decay for representative tests 3,7 and duplicate tests 9 and 10, 
using equation 17 above. It can be seen from Figure $6 \mathrm{~A}$ and $6 \mathrm{~B}$ that the predicted decomposition is in good agreement with the measured 3PB decomposition especially within the first $100 \mathrm{~h}$ duration. The predicted decomposition diverges somewhat at longer times as the predicted decomposition is seen to underestimate the actual measured results. Equation 17 includes an activation energy for this reaction of $82.2 \mathrm{~kJ} / \mathrm{mole}$. A significant level of uncertainty (i.e., at least $20 \%$ ) exists in both the activation energy and the reaction order for copper. Nevertheless, the analysis suggests a copper reaction order significantly different from unity. An integer copper order implies that only a single reaction provides the rate limiting step in the reaction pathway. The observed deviation from unity suggests that a combination of the proposed reactions 4-7 provides a more likely pathway for this decomposition.

Alternatively, this analysis uses a basis of the total copper concentration rather than the soluble copper concentration. Therefore, the conclusion regarding the dependence on copper concentration order could vary when considering only soluble copper as a catalyst. Unfortunately, the experimental work did not monitor the soluble content during the testing.

The measured $2 \mathrm{~PB}$ and $1 \mathrm{~PB}$ concentrations remained below or only slightly above the detection limits in the reaction mixture during decomposition of 3PB. If one assumes a sequential decomposition mechanism proceeding from 3PB through $2 \mathrm{~PB}$ and $1 \mathrm{~PB}$ leading to final products, this result suggests that the decomposition of these intermediates proceeds significantly faster than the copper catalyzed decomposition of 3PB. Measurable quantities of both phenol and benzene formed in tests sealed under air that included significant decomposition of parent 3PB. Only with the highest $0.0084 \mathrm{M}$ quantities of 3PB introduced under highly reactive conditions (see Tests 7 and 8 of Table 5 at $70^{\circ} \mathrm{C}$ ) did the reaction system produce significantly more benzene than phenol, i.e., molar ratios of benzene to phenol $>3$. This observation suggests, under these conditions, possible depletion of the oxygen concentration in the solution by the rapid formation of phenol, thereby shifting the reaction products to benzene. Cast in terms of reactions 4 through 7 , this result suggests both of the reaction pathways of reactions 4-5 and reactions 6-7 may play a significant role in the degradation of $3 \mathrm{~PB}$ with oxygen present.

\section{Diphenylborinic Acid Decomposition}

The data regression indicates that decomposition of 2PB does not depend significantly on the hydroxide concentration. Analysis of the data in Table 6 indicates that 2PB decomposition depends on copper to the approximately $1 / 2$ order. Indication of the repeatability of this decomposition test set is obtained by considering the measured rates from duplicate tests 9 and 10 of Table 6 . Tests 9 and 10 indicate an average decomposition rate of $4.2 \pm 0.64 \times 10^{-5} \mathrm{Mh}^{-1}$. The relative standard deviation for this duplicate test is about $15 \%$. Equation 18 represents the rate expression for the best fit of the experimental data. 


$$
\frac{d[2 P B]}{d t}=-9.4 \times 10^{13} e^{\frac{-82,100}{R T}}\left[C u^{n+}\right]^{0.5}[2 P B]
$$

As indicated in equation 18, the analysis provides an activation energy for this reaction of approximately $82.1 \mathrm{~kJ} /$ mole. Figure 7 (A-C) show comparison of measured 2PB decay versus the predicted 2PB decay using equation 18 above. Reasonable agreement between the predicted and measured 2PB decomposition can be seen from all of the tests shown in Figure 7 A-C. Uncertainty of about $20 \%$ exists in the activation energy and copper order for this reaction. Inspection of reactions 4 through 7 indicates hydroxide appears as a reactant only in reaction 5 . The lack of hydroxide dependence for 2PB decomposition rate suggests that reaction 5 either does not play a significant role in 2PB decomposition, or happens quickly and thus does not govern the overall reaction rate.

\section{Phenylboronic Acid Decomposition}

Analysis of the data in Table 7 for 1PB tests sealed under air indicates that decomposition depends significantly on the total copper present. Indication of the reproducibility of this decomposition test set is obtained by considering the measured rates from duplicate tests 9 and 10 of Table 7 . Tests 9 and 10 indicate an average decomposition rate of $1.1 \pm 0.07 \times 10^{-5} \mathrm{Mh}^{-1}$. The relative standard deviation for this duplicate test is about $7 \%$. Equation 19 represents the rate equation for the best fit of the experimental data.

$$
\frac{d[1 P B]}{d t}=-9.4 \times 10^{18} e^{\frac{-107,000}{R T}}\left[\mathrm{Cu}^{n+}\right]^{0.9}\left[\mathrm{OH}^{-}\right]^{0.7}[1 \mathrm{~PB}]
$$

Figure 8 (A-C) show comparison of measured 1PB decay versus the predicted 1 PB decay using equation 19 above. Figure $8 \mathrm{~A}$ indicates good agreement between predicted and measured 1PB decomposition throughout the entire test. Figure $8 \mathrm{~B}-\mathrm{C}$ shows that predicted decomposition agrees very well with measured within the first $100 \mathrm{~h}$ of testing. At later times the predicted values diverge somewhat by overpredicting the actual measured decomposition. Comparison of equation 19 with equations 17 and 18 indicates a copper order of nearly unit for the $1 \mathrm{~PB}$ rate expression compared to approximately $1 / 2$ order for either $3 \mathrm{~PB}$ or $2 \mathrm{~PB}$. Considered in context of the proposed reaction pathways, this analysis suggests that $1 \mathrm{~PB}$ most likely decomposes by the pathway represented by reactions 4 and 5 . Phenol formed as the primary product observed in all but one of the tests experiencing extensive reaction (i.e., Test 8 of Table 7).

The first four tests at $40^{\circ} \mathrm{C}$ of the 1PB series sealed under air (i.e., Tests 1-4 in Table 7) were repeated in a second series with nitrogen purging of the $\sim 60 \mathrm{~mL}$ vapor space above the solutions immediately before sealing (i.e., Tests 11-14 in 
Table 7). These vapor-space nitrogen-purged tests did not rigorously exclude oxygen since the researchers made no effort to deaerate the solutions and introduced $\sim 5 \mathrm{cc}$ of air into the samples with each analysis step. In the presence of $0.1 \mathrm{mg} / \mathrm{L}$ total added copper, very little decomposition occurred for either the Tests 1 and 4 (sealed under air) or Tests 11 and 14 (sealed under nitrogen) tests. In the presence of $10 \mathrm{mg} / \mathrm{L}$ total added copper, nitrogen purging of the vapor space had the apparent effect of both slowing the overall rate of 1PB decomposition by $\sim 2.5 \mathrm{X}$, and changing the final product distribution from predominately phenol (sealed under air) to benzene (sealed under nitrogen). One interpretation of these results suggests that reducing the amount of oxygen present in air sealed above the solutions by nitrogen-purging shifts the dominant reaction pathway from reactions 4-5 to reactions 6-7.

\section{Decomposition of 2PB and 1PB in Presence of Dissolved Oxygen}

Copper catalyzed tests involving either in situ oxygen monitoring to confirm presence of aerobic solution conditions throughout the reaction period, or constant air flow (solution-purged) conditions, indicate reaction rates of similar magnitude for 2PB and 1PB. Table 8 shows the pseudo-first order rate constants, $\mathrm{k}$ ', for tests conducted in the range of 25 to $60^{\circ} \mathrm{C}$ with $1.5 \mathrm{M} \mathrm{NaOH}$ and $10 \mathrm{mg} / \mathrm{L}$ added copper. Single tests were performed at the higher temperature of $60^{\circ} \mathrm{C}$ and duplicate tests were performed at the lower temperatures of 25 to $40^{\circ} \mathrm{C}$. Precision from the duplicate tests ranged from 4 to $33 \%$. Rate constants were calculated using the simplified rate expressions of,

$\mathrm{d}(\mathrm{x}) / \mathrm{dt}=\mathrm{k}[\mathrm{Cu}][\mathrm{x}]$

$\mathrm{d}(\mathrm{x}) / \mathrm{dt}=\mathrm{k}^{\prime}[\mathrm{x}]$

With $[x]=$ molar concentration of either $2 \mathrm{~PB}$ or $1 \mathrm{~PB}$

Activation energies were estimated from Arrhenius plots of the rate data taken from Table 8 for these tests as shown in Figure 9. The activation energies for these 25 to $60^{\circ} \mathrm{C}$ tests were in the range of $(55 \pm 20)$ to $(72 \pm 2) \mathrm{kJ} /$ mole for $2 \mathrm{~PB}$ and $1 \mathrm{~PB}$, respectively, i.e., lower than determined for the tests sealed under air as shown in equations 18 and 19, respectively. These results that estimate a lower activation energy in the constant presence of air indicate that aerobic dephenylation of $2 \mathrm{~PB}$ and $1 \mathrm{~PB}$ occurs more readily than in tests sealed under air, or partially oxygenated tests with $2 \mathrm{~PB}$ and $1 \mathrm{~PB}$. One interpretation of these results suggests a dominant reaction pathway described by reactions $4-5$ for decomposition of both $2 \mathrm{~PB}$ and $1 \mathrm{~PB}$ in aerobic copper-containing alkaline solutions.

\section{Comparison of Phenylborate Rate Expressions}

Decomposition rates based on pseudo first order rate constants at fixed copper concentration increase in the order of NaTPB $<1$ PB $\sim 3$ PB $<2$ PB . Table 9 shows the pseudo-first order rate constants, $\mathrm{k}^{\prime}$, calculated for intermediate test 
conditions of $55^{\circ} \mathrm{C}, 1 \mathrm{mg} / \mathrm{L}$ added copper and $1.5 \mathrm{M}$ hydroxide. The simplified rate expressions of equations 20 and 21 were used with the numerical values (pre-exponential factors, activation energies and copper and hydroxide order dependencies ) in equations $16,17,18$ and 19 to calculate the rate constants shown in Table 9 for NaTPB, 3PB, 2PB and 1PB, respectively. The variability shown for each rate constant in Table 9 is derived from consideration of both the deviation associated from duplicate test runs for each phenylborate system and from the level of uncertainty, i.e., variance in activation energy and copper order dependencies, associated with development of the kinetic expressions in equations 16-19.

Present tests investigating effects of copper concentrations on 3PB, 2PB and $1 \mathrm{~PB}$, considered with present NaTPB and previous NaTPB tests [8], indicate the order of dependence on total copper increases in the order of $3 \mathrm{~PB} \sim 2 \mathrm{~PB}<1 \mathrm{~PB}$ $\sim$ NaTPB. These analyses also indicate the activation energies for these systems fall between 82 and $143 \mathrm{~kJ} /$ mole and increase in the order of 3PB $2 \mathrm{~PB}<1 \mathrm{~PB}<\mathrm{NaTPB}$. Researchers found no statistically significant dependencies on the hydroxide concentration over the range of $0.1-2.5 \mathrm{M} \mathrm{OH}^{-}$ in these tests for NaTPB, 3PB and 2PB. However, data regression suggested a fractional positive order dependence for 1PB.

Kinetic expressions developed in the present study have been compared to recent facility tests $[5,6]$ at the Savannah River Site. Decomposition rates calculated from copper-catalyzed kinetic expressions for NaTPB and 3PB are several orders of magnitude lower than estimates from large-scale plant processing verification tests. Similar comparisons indicate 2PB and $1 \mathrm{~PB}$ decomposition rates of the same order of magnitude as observed from facility tests. These results suggest that perhaps some species other than copper caused the rapid degradation of NaTPB and 3PB in the facility. Recent testing in this laboratory aimed at identifying catalysts other than copper showed that palladium also catalyzes NaTPB decomposition under our aqueous alkaline test conditions.

\section{CONCLUSIONS}

Studies of the copper-catalyzed chemical kinetics of the decomposition of tetraphenylborate ion, triphenylborane, diphenylborinic acid and phenylboronic acid in aqueous alkaline solution between 25 and $70^{\circ} \mathrm{C}$ showed the stability of all three intermediates in alkaline solution $(\mathrm{pH}>13)$ when kept at ambient temperature in the absence of copper. Significant decomposition of these species occurs in the presence of copper concentrations of 0.1 to $10 \mathrm{mg} / \mathrm{L}$. Each phenylborate species studied completely decomposed at $70^{\circ} \mathrm{C}$ in presence of total added copper ( $10 \mathrm{mg} / \mathrm{L}$ ) within 300 hours.

The decomposition rates based on pseudo first order rate constants at fixed copper concentration increase in the order of NaTPB $<3 \mathrm{~PB} \sim 1 \mathrm{~PB}<2 \mathrm{~PB}$. The order of dependence on total copper increases in the order of $3 \mathrm{~PB} \sim 2 \mathrm{~PB}<1 \mathrm{~PB}$ 
$\sim$ NaTPB. We discussed kinetic rate expressions for reaction pathways involving both a redox process with hydroxide and copper reactants (reactions 45 ), and dephenylation by reduced cuprous ion involving a phenylated copper organometallic intermediate (reactions 6-7). Increased decomposition rates in the presence of oxygen for 3PB, 2PB and 1PB suggest that oxidation of copper (i.e., the sequence of reactions 4-5) may play a significant role in governing the rate of decomposition. Copper catalyzed decomposition of NaTPB in air saturated systems appears inhibited, or delayed, relative to prompt decomposition observed in anoxic solutions. This result suggests that decomposition of NaTPB via the sequence of reactions 4-5 occurs to a significantly lesser extent than by the sequence of reactions 6-7 involving the reduced phenylated copper intermediate.

The kinetic rate expressions developed in this investigation were applied to decomposition data for the various phenylborate species in facility operations. Decomposition rates calculated from copper-catalyzed kinetic expressions for NaTPB and 3PB are several orders of magnitude lower than estimates from large-scale plant processing verification tests. Comparisons also indicate that 2PB and 1PB decomposition rates of the same order of magnitude as observed from facility tests.

\section{ACKNOWLEDGMENTS}

The authors wish to express their gratitude to Ms. K. L. Prettel and Ms. B. H. Croy, who prepared most of the samples and performed much of the sampling of the tests for subsequent analyses. The authors also express their appreciation to Dr. C. W. Hsu and Dr. T. L. White of the Savannah River Technology Center Analytical Development Section for their HPLC methodology development and thorough analytical support. 


\section{REFERENCES}

[1] H. D. Martin, M. A. Schmitz, M. A. Ebra, D. D. Walker, L. L. Kilpatrick and L.-M. Lee, Proc. Symposium on Waste Management ' 84 , Waste Isolation in the U. S. Technical Programs and Public Education, March 11-15, 1984, Tucson AZ, Edited by R. G. Post, Sponsored by American Nuclear Society, Vol. 1, Waste Policies and Programs, High-Level Waste, (1984) 291.

[2] P. D. d'Entremont and D. D. Walker, Proc. Symposium on Waste Management '87, Waste Isolation in the U.S. Technical Programs and Public Education, March 1-5, 1987, Tucson, AZ, Edited by R. G. Post, Sponsored by American Nuclear Society, Vol. 2, High-Level Waste, (1987) 69.

[3] D. D. Walker and E. L. Wilhite, Proc. First Annual International HighLevel Radioactive Waste Management Conference, April 8-12, 1990, Las Vegas, NV, Sponsored by American Soc. Of Civil Engineers and the American Nuclear Society, Published by American Nuclear Society, La Grange Park, IL and American Society of Civil Engineers, New York, NY, Vol. 2 (1990) 1110.

[4] L.-M. Lee and L. L. Kilpatrick, United States Patent \#4,432,893 (1984).

[5] D. D. Walker, M. J. Barnes, C. L. Crawford, R. A. Peterson, R. F. Swingle and S. D. Fink, Proceedings of the $214^{\text {th }}$ American Chemical Society National Meeting, Las Vegas, NV, September 7-11, 1997. Published in Science and Technology for Disposal of Radioactive Tank Wastes, Plenum, NY, 1998, pp. 217-228.

[6] R. Robinson, J. Sanders, L. Miyoshi, K. Fortenberry and R. Zavadoski, Defense Nuclear Facilities Safety Board Technical Report, DNFSB/TECH-14, Rev. 2, June 1997. This Defense Nuclear Facilities Safety Board Technical Report can be found on the world wide web at: http://www.dnfsb.gov/techrpts/tech14.htm

[7] S. S. Cooper, Analytical Chemistry, 29 (1957) 446.

[8] M. J. Barnes, Proc. Symposium on Waste Management '91, Waste Processing, Transportation, Storage and Disposal, Technical Programs and Public Education, February 24-28, 1991, Tucson, AZ, Edited by R. G. Post, Sponsored by American Nuclear Society, Vol. 1, Programmatic, Communications and Environmental Restoration, (1991) 759.

[9] J. N. Cooper and R. E. Powell, J. Am. Chem. Soc., 85 (1963) 1590.

[10] V. A. Simon, Ph. D. Dissertation, Florida State University, Dissertation Abstr., 23 (1962) 1534. 
Page 20 of 35

[11] J. P. Doherty and J. C. Marek, United States Patent \#4,840,765 (1989).

[12] C. J. Bannochie, J. C. Marek, R. E. Eibling and M. A. Baich, ACS Symp. Ser. Emerging Technologies in Hazardous Waste Management IV, 554 (1994) 285.

[13] J. J. Eisch and R. J. Wilcsek, J. of Organometal. Chem. 71 (1974) C21.

[14] P. Abley and J. Halpern, J. Chem. Soc., Chem. Commun., (1971) 1238.

[15] G. A. Razuvaev and T. G. Brikina, J. of Gen. Chem. USSR, 26 (1954) 1397.

[16] J. L. R. Williams J. C. Doty, P. J. Grisdale, R. Searle, T. H. Regan, G. P. Happ and D. P. Maier, J. Am. Chem. Soc., 89 (1967) 5153.

[17] J. L. R. Williams, J. C. Doty, P. J. Grisdale, T. H. Reagan, G. P. Happ and D. P. Maier, J. Am. Chem. Soc., 90 (1968) 53.

[18] J. C. Doty, P. J. Grisdale, T. R. Evans and J. L. R. Williams, J. Organometal. Chem. 32 (1971) C35.

[19] J. L. R. Williams J. C. Doty, P. J. Grisdale, T. H. Regan and D. G. Borden, J. Chem. Soc., Chem. Commun., (1967) 109.

[20] D. H. Geske, J. Phys. Chem., 63 (1959) 1062.

[21] D. H. Geske, J. Phys. Chem., 66 (1962) 1743.

[22] H. Horii and S. Taniguchi, J. Chem. Soc., Chem. Commun. (1986) 915.

[23] A. K. Gupta, R. J. Hanrahan and D. D. Walker, J. Phys. Chem., 95 (1991) 3590.

[24] A. K. Gupta, R. J. Hanrahan and D. D. Walker, Radiochim. Acta, 60 (1993) 43.

[25] C. L. Crawford, M. R. Gholami, R. N. Bhave and R. J. Hanrahan, Radiat. Phys. Chem., 44 (1994) 309.

[26] G. Wittig and P. Raff, Ann., 573 (1951) 195.

[27] A. N. Nesmeyanov and V. A. Sazonova, Bull. Aca. Sci. USSR, Div. Chem. Sci., 42 (1955).

[28] V. A. Sazonova and I. I. Nazarova, J. of Gen. Chem. USSR, 26, (1956) 3829.

[29] G. Costa, A. Camus, N. Marsich and L. Gatti, J. Organometal. Chem., 8 (1967) 339. 
[30] G. Costa, A. Camus, L. Gatti and N. Marsich, J. Organometal. Chem., 5 (1966) 568.

[31] H. C. Brown and V. H. Dodson, J. Chem. Soc., 79 (1957) 2302.

[32] N. V. Sidgwick, The Chemical Elements and Their Compounds, Vol. I., Oxford University Press, London, 1949, p. 370.

[33] Z. K. Urtaeva, A. A. Bumber, O. Y. Okhlobystin, Dokl. Akad. Nauk. SSSR Engl. Transl., 286 (1986) 85.

[34] Z. K. Urtaeva, A. A. Bumber, O. Y. Okhlobystin, Zhur. Obshch. Khim. Engl. Transl., 56 (1986) 1142.

[35] O. Kajimoto, T. Saeki, Y. Nagaoka and T. Fueno, J. Phys. Chem., 81 (1977) 1712.

[36] R. D. Pizer and P. J. Ricatto and C. A. Tihal, Polyhedron, 12 (1993) 2137.

[37] B. W. Hatt, Chem. Ind., (1975) 617.

[38] A. D. Ainley and F. Challenger, J. Chem. Soc., (1930) 2171.

[39] H. G. Kuivila and K. V. Nahabedian, J. Am. Chem. Soc., 83 (1961) 2159.

[40] H. G. Kuivila, J. F. Reuwer Jr. and J. A. Mangravite, J. Am. Chem. Soc., 86 (1964) 2666.

[41] SAS Institute, JMP Statistics and Graphics Guide, Version 3, SAS Institute Inc., Cary, NC, 1994.

[42] R. L. Mason, R. F. Gunst and J. L. Hess, Statistical Design and Analysis of Experiments with Application to Engineering and Science, John Wiley \& Sons, New York, 1989.

[43] C. W. Hsu and T. L. White, J. Chromatography A, (1998) in press. 
Table 1

Statistical Design of NaTPB Decomposition Tests.

\begin{tabular}{|c|c|c|c|c|c|}
\hline Test ID & $\underline{\text { NaTPB }}$ & $\underline{\mathrm{NaOH}}$ & Temperature & Oxygen & $\frac{\text { Total }}{\text { Copper }}$ \\
\hline 1 & -1 & -1 & -1 & -1 & 0 \\
\hline 2 & -1 & -1 & 1 & 1 & 0 \\
\hline 3 & -1 & 1 & -1 & 1 & 0 \\
\hline 4 & -1 & 1 & 1 & -1 & 0 \\
\hline 5 & 1 & -1 & -1 & 1 & 0 \\
\hline 6 & 1 & -1 & 1 & -1 & 0 \\
\hline 7 & $1^{*}$ & $1^{*}$ & -1 & -1 & 0 \\
\hline 8 & $1^{*}$ & $1^{*}$ & 1 & 1 & 0 \\
\hline 9 & 0 & 0 & 0 & 0 & 0 \\
\hline 10 & 0 & 0 & 0 & 0 & 0 \\
\hline 11 & 1 & -1 & 1 & 1 & 0 \\
\hline 12 & 1 & -1 & 1 & -1 & 0 \\
\hline
\end{tabular}

Temperatures at 40,55 , and $70^{\circ} \mathrm{C}$;

$\mathrm{NaTPB}=0.001,0.02,0.23$ and $0.5 \mathrm{M}$;

Hydroxide concentration $=0.1,0.5,1.2$ and $2.5 \mathrm{M}$;

Oxygen = 0, 5 and 21 vol\%;

Copper(II) added as soluble $\mathrm{Cu}\left(\mathrm{NO}_{3}\right)_{2} \cdot 6 \mathrm{H}_{2} \mathrm{O}$ solution $=10 \mathrm{mg} / \mathrm{L}$.

* Note that in Tests 7 and 8, it is impossible, due to solubility limitations, to have both a high tetraphenylborate concentration and a high hydroxide concentration. For this reason, these experiments lowered the concentrations of each component to accommodate the solubility limit for the tetraphenylborate while maintaining both species at relatively high values.

Table 2

Statistical Design of 3PB, 2PB and 1PB Tests Sealed Under Air.

\begin{tabular}{|c|c|c|c|c|}
\hline Test ID & Temperature & Organic & $\mathrm{NaOH}$ & Total Copper \\
\hline 1 & -1 & -1 & $\frac{-1}{-1}$ & -1 \\
\hline 2 & -1 & -1 & 1 & 1 \\
\hline 3 & -1 & 1 & -1 & 1 \\
\hline 4 & -1 & 1 & 1 & -1 \\
\hline 5 & 1 & -1 & -1 & 1 \\
\hline 6 & 1 & -1 & 1 & -1 \\
\hline 7 & 1 & 1 & -1 & -1 \\
\hline 8 & 1 & 1 & 1 & 1 \\
\hline 9 & 0 & 0 & 0 & 0 \\
\hline 10 & 0 & 0 & 0 & 0 \\
\hline
\end{tabular}

Temperatures at 40,55 , and $70^{\circ} \mathrm{C}$;

Organic Reagent (3PB, 2PB or 1PB) $=0.0008,0.003$, and 0.008;

Hydroxide concentration $=0.5,1.5$, and 2.5 Molar;

Copper(II) added as soluble $\mathrm{CuSO}_{4} \cdot 5 \mathrm{H}_{2} \mathrm{O}$ solution $=0.1,1$, and $10 \mathrm{mg} / \mathrm{L}$. 
Table 3

Thermal Hydrolysis of Phenylborates (in absence of copper).

\begin{tabular}{ccccccc} 
Organic & $\begin{array}{c}\text { Hydroxide } \\
(\mathrm{M})\end{array}$ & $\begin{array}{c}\text { Sodium } \\
(\mathrm{M})\end{array}$ & $\begin{array}{c}\text { Temperature } \\
\left({ }^{\circ} \mathrm{C}\right)\end{array}$ & $\begin{array}{c}\text { Time } \\
(\mathrm{h})\end{array}$ & $\begin{array}{c}\text { Percent } \\
\text { Decomposed }\end{array}$ & $\begin{array}{c}\text { Rate Constant } \\
\left(\mathrm{h}^{-1}\right)\end{array}$ \\
\hline NaTPB & 0.6 & 2.0 & 70 & 168 & 13 & 0.00087 \\
3PB & 1.5 & 1.5 & $23-25$ & 500 & 8 & 0.00018 \\
2PB & 0.6 & 2.0 & 70 & 168 & 37 & 0.0021 \\
2PB & 0.6 & 2.0 & 70 & 168 & 27 & 0.0019 \\
2PB & 2.3 & 4.7 & 55 & 800 & 71 & 0.0013 \\
2PB & 1.5 & 1.5 & $23-25$ & 375 & 2 & $<0.00007$ \\
1PB & 0.6 & 2.0 & 70 & 168 & 29 & 0.0021 \\
1PB & 1.5 & 1.5 & $23-25$ & 350 & 2 & $<0.00007$
\end{tabular}

Table 4

Summary of Rates of Reaction and Rate Constants Obtained from Copper-Catalyzed NaTPB Decomposition Tests.

\begin{tabular}{|c|c|c|c|c|c|c|}
\hline$\frac{\text { Test }}{\underline{\text { ID }}}$ & $\begin{array}{c}\text { Temperature } \\
\left({ }^{\circ} \mathrm{C}\right)\end{array}$ & $\begin{array}{l}\operatorname{NaTPB} \\
(\underline{\mathrm{M}})\end{array}$ & $\begin{array}{l}\text { Rate of NaTPB } \\
\text { Decomposition } \\
\left(\mathrm{Mh}^{-1}\right)\end{array}$ & $\begin{array}{c}\text { Rate } \\
\text { Constant, } \mathrm{k} \\
\left(\mathrm{M}^{-1} \mathrm{~h}^{-1}\right)\end{array}$ & $\ln (k)$ & $\begin{array}{c}1 / \mathrm{RT} \\
\text { (mole/kJ) } \\
\end{array}$ \\
\hline 1 & 40 & 0.001 & $1.1 \times 10^{-8}$ & 0.070 & -2.7 & 0.38 \\
\hline 2 & 70 & 0.001 & $42 \times 10^{-7}$ & 2.7 & 0.98 & 0.35 \\
\hline 3 & 40 & 0.001 & $1.6 \times 10^{-9}$ & 0.011 & -4.6 & 0.38 \\
\hline 4 & 70 & 0.001 & $3.8 \times 10^{-7}$ & 2.4 & 0.88 & 0.35 \\
\hline 5 & 40 & 0.5 & $3.9 \times 10^{-4}$ & 4.4 & 1.6 & 0.38 \\
\hline 6 & 70 & 0.5 & $6.4 \times 10^{-3}$ & 75 & 4.4 & 0.35 \\
\hline 7 & 40 & 0.23 & $6.9 \times 10^{-6}$ & 0.19 & -1.6 & 0.38 \\
\hline 8 & 70 & 0.23 & $6.9 \times 10^{-4}$ & 49 & 2.9 & 0.35 \\
\hline 9 & 55 & 0.02 & $7.8 \times 10^{-6}$ & 1.9 & 0.91 & 0.37 \\
\hline 10 & 55 & 0.02 & $7.6 \times 10^{-6}$ & 2.3 & 0.88 & 0.37 \\
\hline 11 & 70 & 0.5 & $4.9 \times 10^{-3}$ & 62 & 4.1 & 0.35 \\
\hline 12 & 70 & 0.5 & $7.4 \times 10^{-3}$ & 94 & 4.5 & 0.35 \\
\hline
\end{tabular}


WSRC-MS-98-00876, Rev. 0

Page 24 of 35

Table 5

Reaction Rate Data for 3PB Decomposition in the Presence of Air.

$\begin{array}{ccccccc}\text { Test ID } & \begin{array}{c}\text { Temperature } \\ \frac{\left({ }^{\circ} \mathrm{C}\right)}{1}\end{array} & \begin{array}{c}3 \mathrm{~PB} \\ (\mathrm{M})\end{array} & \begin{array}{c}\mathrm{OH}^{-} \\ (\mathrm{M})\end{array} & \begin{array}{c}\mathrm{Cu}(\mathrm{II}) \\ (\mathrm{mg} / \mathrm{L})\end{array} & \begin{array}{c}\text { Final Molar Ratios } \\ \text { (Benzene/ } \\ \text { Phenol) }\end{array} & \begin{array}{c}\text { Rate of 3PB } \\ \text { Decomposition } \\ \left(\mathrm{Mh}^{-1}\right)\end{array} \\ 2 & 40 & 0.00084 & 0.5 & 0.1 & 1.5 & 2.5 \times 10^{-7} \\ 3 & 40 & 0.00084 & 2.5 & 10 & 0.23 & 4.6 \times 10^{-7} \\ 4 & 40 & 0.0084 & 0.5 & 10 & 0.97 & 1.4 \times 10^{-5} \\ 5 & 40 & 0.0084 & 2.5 & 0.1 & 0.45 & 4.5 \times 10^{-6} \\ 6 & 70 & 0.00084 & 0.5 & 10 & 0.45 & 1.5 \times 10^{-5} \\ 7 & 70 & 0.00084 & 2.5 & 0.1 & 0.47 & 1.0 \times 10^{-6} \\ 8 & 70 & 0.0084 & 0.5 & 0.1 & 3.3 & 2.0 \times 10^{-5} \\ 9 & 70 & 0.0084 & 2.5 & 10 & 6.2 & 6.7 \times 10^{-5} \\ 10 & 55 & 0.0030 & 1.5 & 1 & 0.40 & 2.6 \times 10^{-6} \\ & 55 & 0.0030 & 1.5 & 1 & 0.23 & 1.5 \times 10^{-6}\end{array}$

Table 6

Reaction Rate Data for 2PB Decomposition in the Presence of Air.

\begin{tabular}{|c|c|c|c|c|c|c|}
\hline Test ID & $\begin{array}{l}\text { Temp. } \\
\left({ }^{\circ} \mathrm{C}\right)\end{array}$ & $\begin{array}{c}2 \mathrm{~PB} \\
(\mathrm{M})\end{array}$ & $\begin{array}{l}\mathrm{OH}- \\
(\mathrm{M})\end{array}$ & $\begin{array}{l}\mathrm{Cu}(\mathrm{II}) \\
(\mathrm{mg} / \mathrm{L}) \\
\end{array}$ & $\begin{array}{l}\text { Final Molar Ratios } \\
\text { (Benzene/ } \\
\text { Phenol) }\end{array}$ & $\begin{array}{l}\text { Rate of 2PB } \\
\text { Decomposition } \\
\left(\mathrm{Mh}^{-1}\right)\end{array}$ \\
\hline 1 & 40 & 0.00084 & 0.5 & 0.1 & 3.8 & $5.5 \times 10^{-7}$ \\
\hline 2 & 40 & 0.00084 & 2.5 & 10 & 0.92 & $1.4 \times 10^{-5}$ \\
\hline 3 & 40 & 0.0086 & 0.5 & 10 & 1.9 & $1.5 \times 10^{-4}$ \\
\hline 4 & 40 & 0.0086 & 2.5 & 0.1 & 0.71 & $6.4 \times 10^{-5}$ \\
\hline 5 & 70 & 0.00084 & 0.5 & 10 & 1.4 & $1.9 \times 10^{-5}$ \\
\hline 6 & 70 & 0.00084 & 2.5 & 0.1 & 0.66 & $1.7 \times 10^{-5}$ \\
\hline 7 & 70 & 0.0084 & 0.5 & 0.1 & 3.0 & $1.9 \times 10^{-4}$ \\
\hline 8 & 70 & 0.0084 & 2.5 & 10 & 5.8 & $2.0 \times 10^{-4}$ \\
\hline 9 & 55 & 0.0031 & 1.5 & 1 & 0.51 & $3.7 \times 10^{-5}$ \\
\hline 10 & 55 & 0.0031 & 1.5 & 1 & 0.65 & $4.6 \times 10^{-5}$ \\
\hline
\end{tabular}


Table 7

Reaction Rate Data for 1PB Decomposition in the Presence of Air.

\begin{tabular}{ccccccc} 
Test ID & $\begin{array}{c}\text { Temperature } \\
\left({ }^{\circ} \mathrm{C}\right)\end{array}$ & $\begin{array}{c}1 \mathrm{~PB} \\
(\mathrm{M})\end{array}$ & $\begin{array}{c}\mathrm{OH}^{-} \\
(\mathrm{M})\end{array}$ & $\begin{array}{c}\mathrm{Cu}(\mathrm{II}) \\
(\mathrm{mg} / \mathrm{L})\end{array}$ & $\begin{array}{c}\text { Final Molar Ratios } \\
\text { (Benzene/ } \\
\text { Phenol) }\end{array}$ & $\begin{array}{c}\text { Rate of 1PB } \\
\text { Decomposition } \\
\left(\mathrm{Mh}^{-1}\right)\end{array}$ \\
2 & 40 & 0.00075 & 0.5 & 0.1 & 1.1 & $5.7 \times 10^{-7}$ \\
3 & 40 & 0.00075 & 2.5 & 10 & 0.10 & $5.3 \times 10^{-6}$ \\
4 & 40 & 0.015 & 0.5 & 10 & 0.10 & $5.1 \times 10^{-5}$ \\
5 & 40 & 0.015 & 2.5 & 0.1 & 0.10 & $5.1 \times 10^{-6}$ \\
6 & 70 & 0.00075 & 0.5 & 10 & 0.40 & $5.8 \times 10^{-6}$ \\
7 & 70 & 0.00075 & 2.5 & 0.1 & 0.56 & $1.3 \times 10^{-5}$ \\
8 & 70 & 0.015 & 0.5 & 0.1 & 0.10 & $7.6 \times 10^{-6}$ \\
9 & 70 & 0.015 & 2.5 & 10 & 3.1 & $1.7 \times 10^{-4}$ \\
10 & 55 & 0.0035 & 1.5 & 1 & 0.10 & $1.0 \times 10^{-5}$ \\
$11^{*}$ & 55 & 0.0035 & 1.5 & 1 & 0.10 & $1.1 \times 10^{-5}$ \\
$12^{*}$ & 40 & 0.00075 & 0.5 & 0.1 & 1.3 & $1.4 \times 10^{-7}$ \\
$13^{*}$ & 70 & 0.00075 & 2.5 & 10 & 3.9 & $2.0 \times 10^{-6}$ \\
$14^{*}$ & 40 & 0.015 & 0.5 & 10 & 4.5 & $2.5 \times 10^{-5}$ \\
\hline
\end{tabular}

*Tests 11-14 were sealed under nitrogen prior to start of tests, see text.

Table 8

Summary of Pseudo-First Order Rate Constants Obtained from Copper-Catalyzed 2PB and 1PB Decomposition Tests in Continuous Presence of Dissolved Oxygen.

\begin{tabular}{|c|c|c|}
\hline $\begin{array}{c}\text { Temperature } \\
\left.{ }^{\circ} \mathrm{O}\right)(\end{array}$ & $\begin{array}{c}\text { 2PB Rate } \\
\text { Constant, } \mathrm{k}^{\prime} \\
\left(\mathrm{h}^{-1}\right)\end{array}$ & $\begin{array}{c}\text { 1PB Rate } \\
\text { Constant, } \mathrm{k}^{\prime} \\
{\left(\mathrm{h}^{-1}\right)}^{2}\end{array}$ \\
\hline 60 & 0.19 & 0.19 \\
\hline 40 & $0.026 \pm 0.001$ & $0.038 \pm 0.003$ \\
\hline 25 & $0.019 \pm 0.004$ & $0.009 \pm 0.003$ \\
\hline
\end{tabular}


Table 9

Summary of Pseudo-First Order Rate Constants Obtained from Copper-Catalyzed NaTPB, 3PB, 2PB and 1PB Decomposition Tests.

\begin{tabular}{ccc} 
Component & $\begin{array}{c}\text { Rate* } \\
\text { Constant, k' } \\
\left(\mathrm{h}^{-1}\right)\end{array}$ & Variability** $^{* *}$ \\
NaTPB & $2.9 \times 10^{-5}$ & $10-24 \%$ \\
3PB & $2.4 \times 10^{-3}$ & $20-38 \%$ \\
2PB & $3.1 \times 10^{-2}$ & $15-20 \%$ \\
1PB & $5.4 \times 10^{-3}$ & $7-20 \%$ \\
\hline
\end{tabular}

*Rate constants calculated from Equations 16, 17, 18 and 19 for NaTPB, 3PB, 2PB and 1PB, respectively.

**The value claimed for variability derives from consideration of deviation in duplicate tests and from the level of uncertainty associated with development of the kinetic expressions in equations 16-19.

All rates calculated using similar intermediate test conditions of $55^{\circ} \mathrm{C}, 1 \mathrm{mg} / \mathrm{L}$ added copper and 1.5 M hydroxide. 
Figure 1. Arrhenius Plot of NaTPB Decomposition

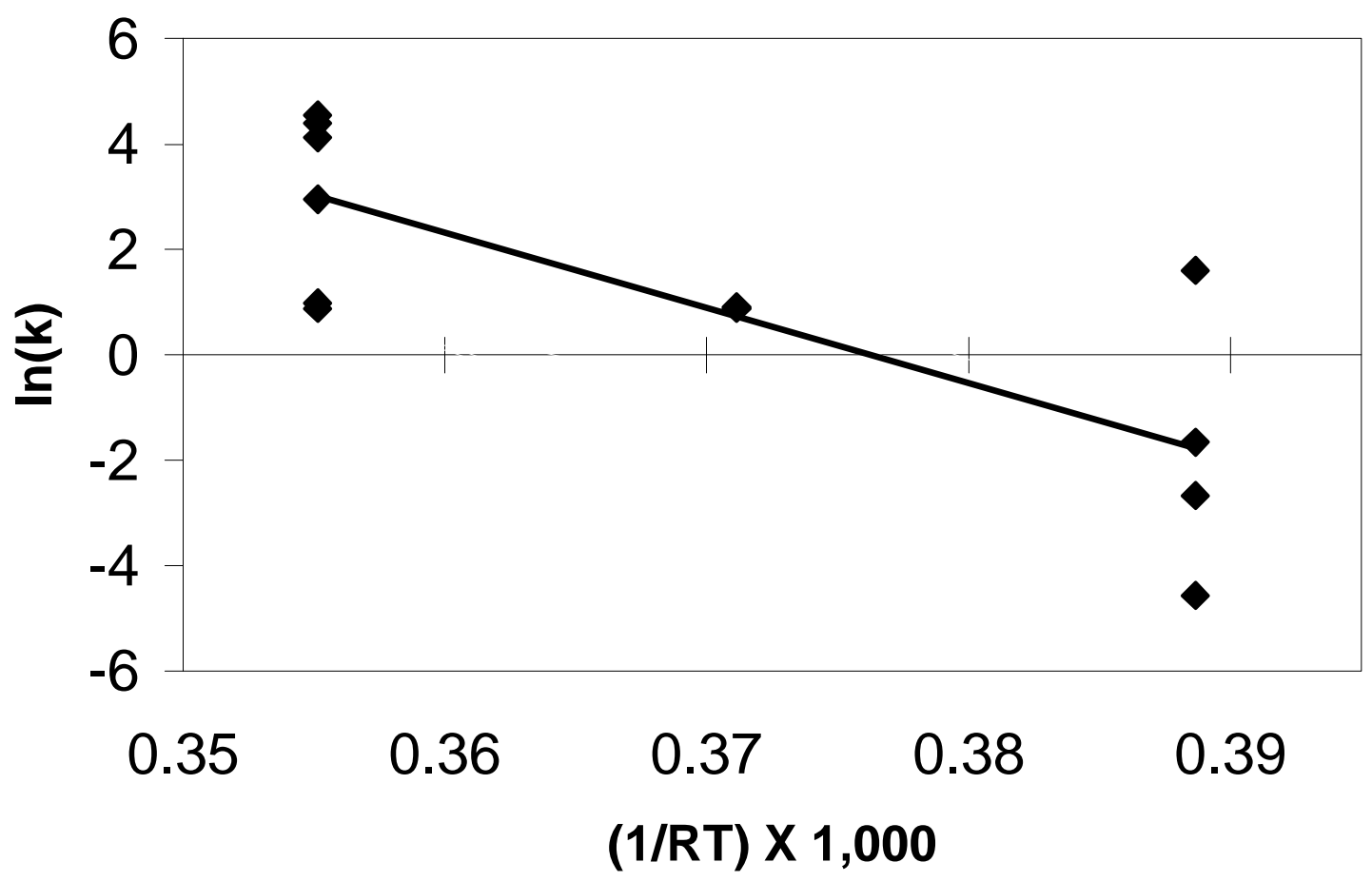


Figure 2. Decomposition of NaTPB in Air-Ventilated Test

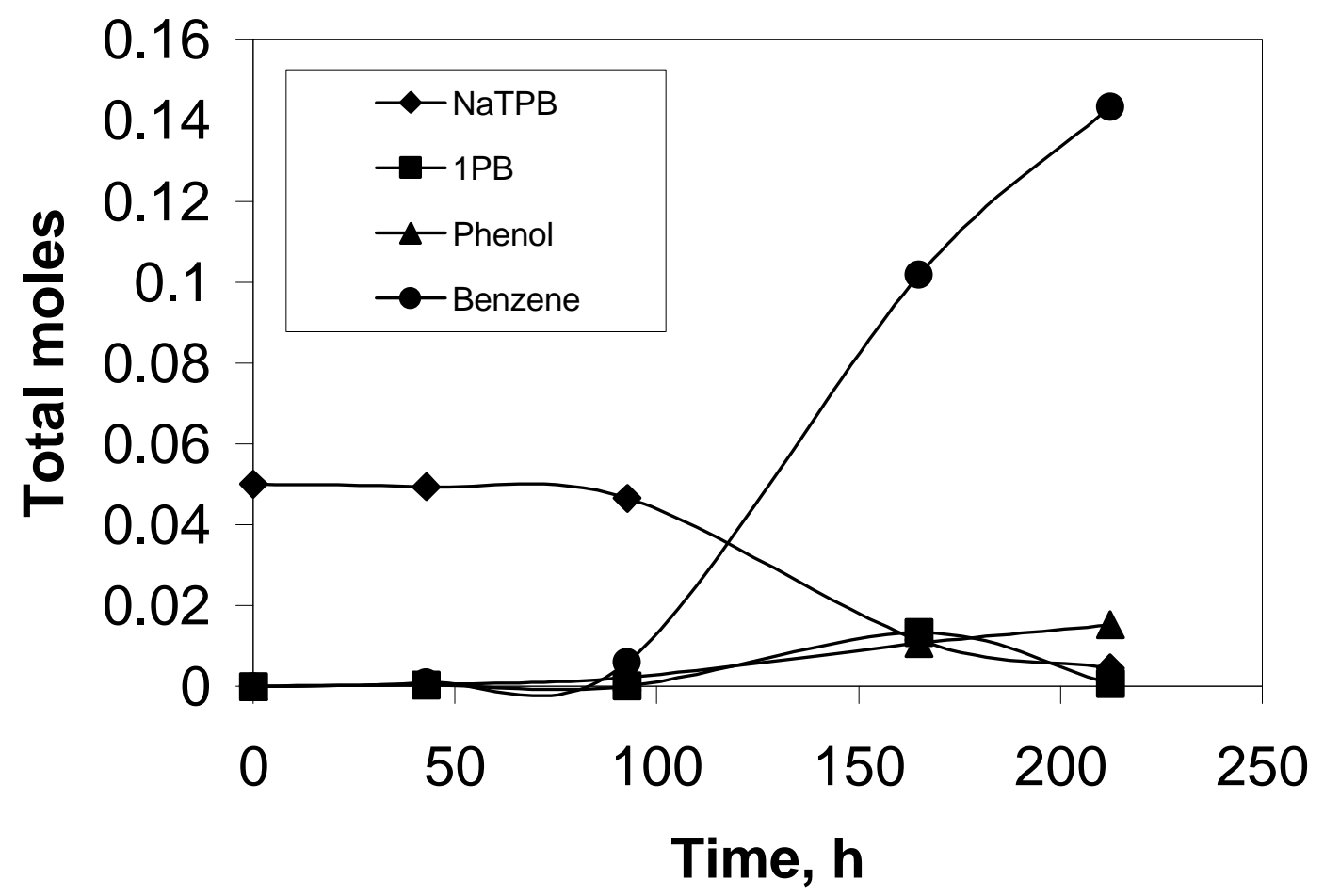


Figure 3. Decomposition of NaTPB in Nitrogen-Ventilated Test

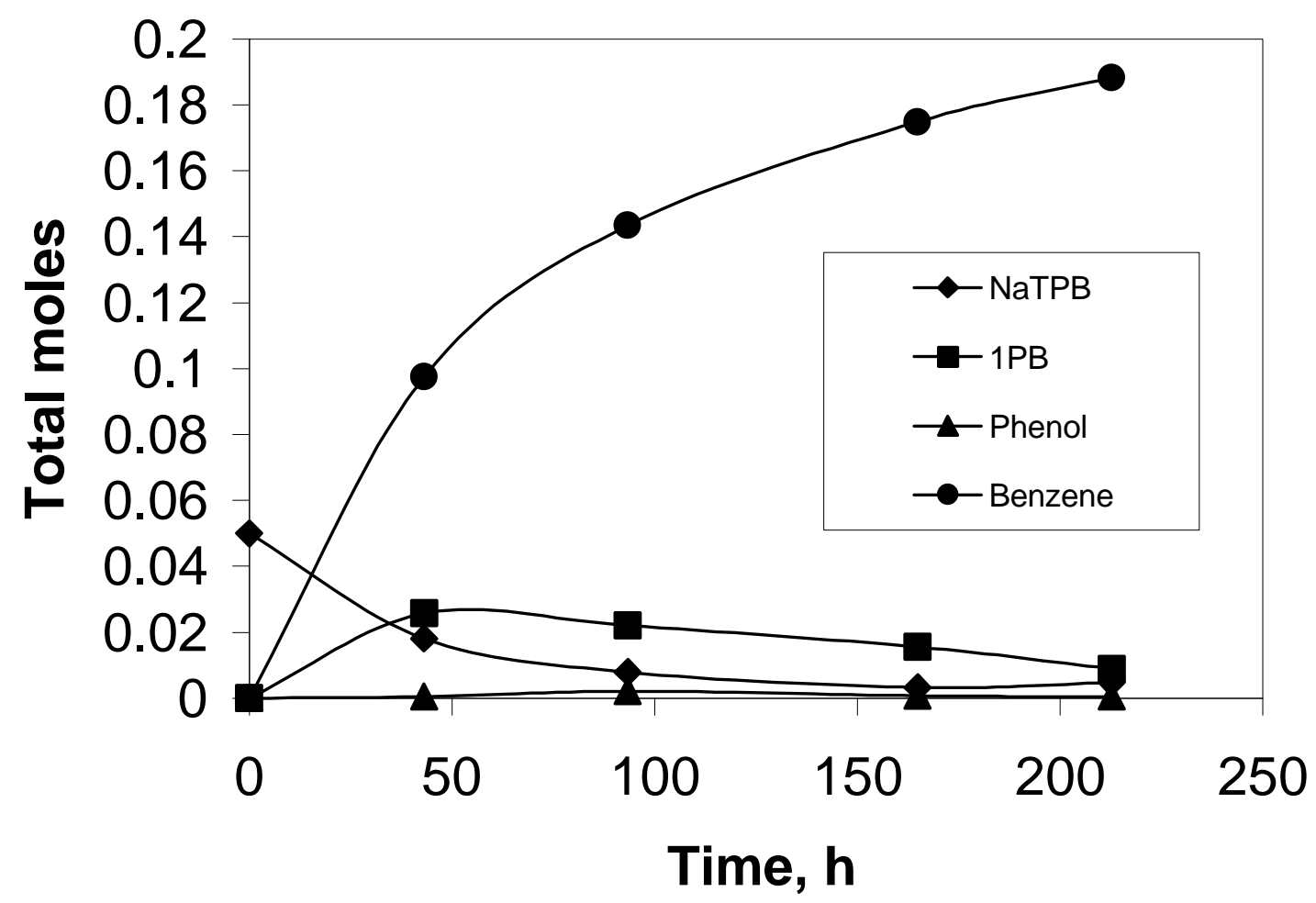


Figure 4. Decomposition of NaTPB in Sealed Aerated Test

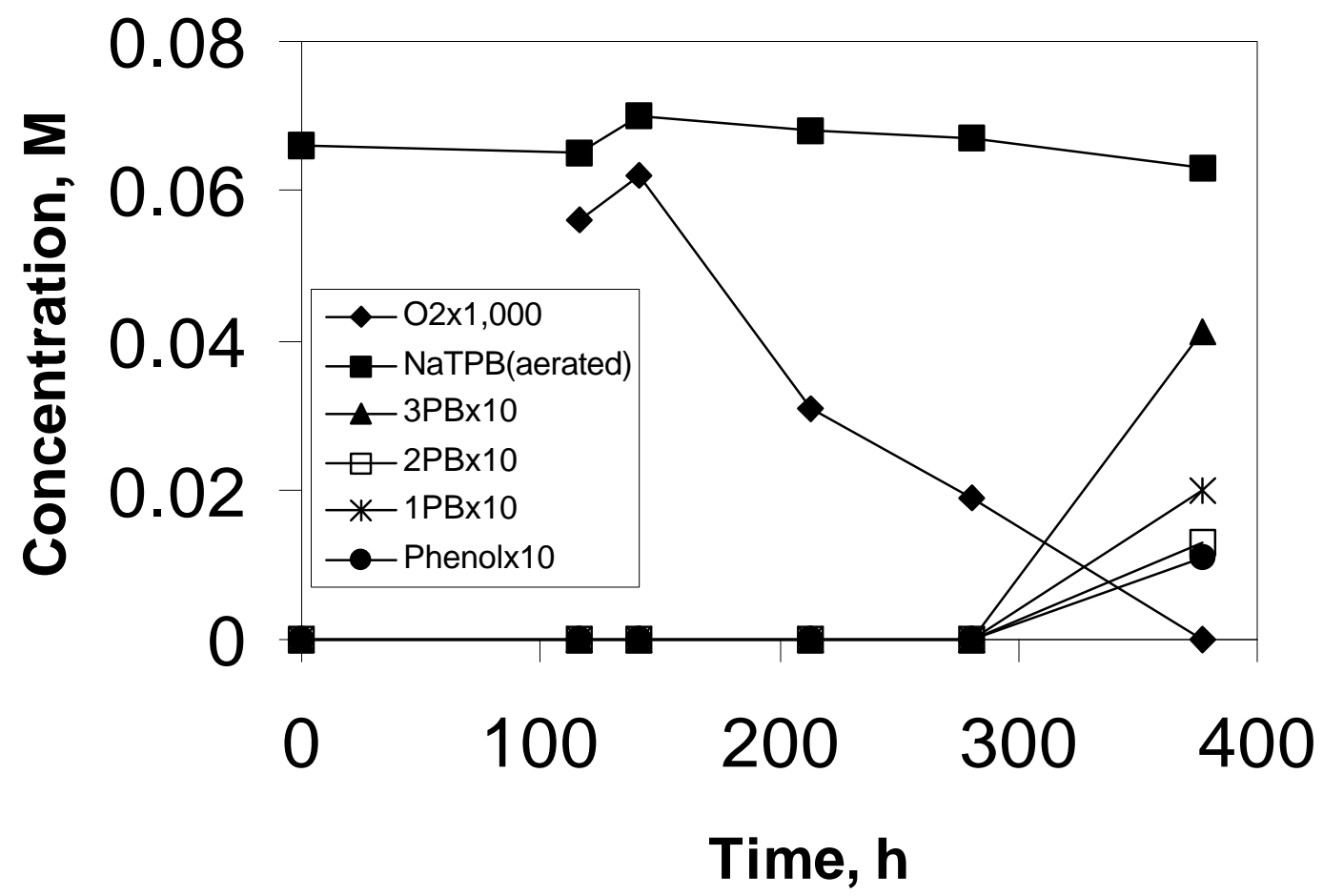


Figure 5. Decomposition of NaTPB in Sealed Deaerated Test

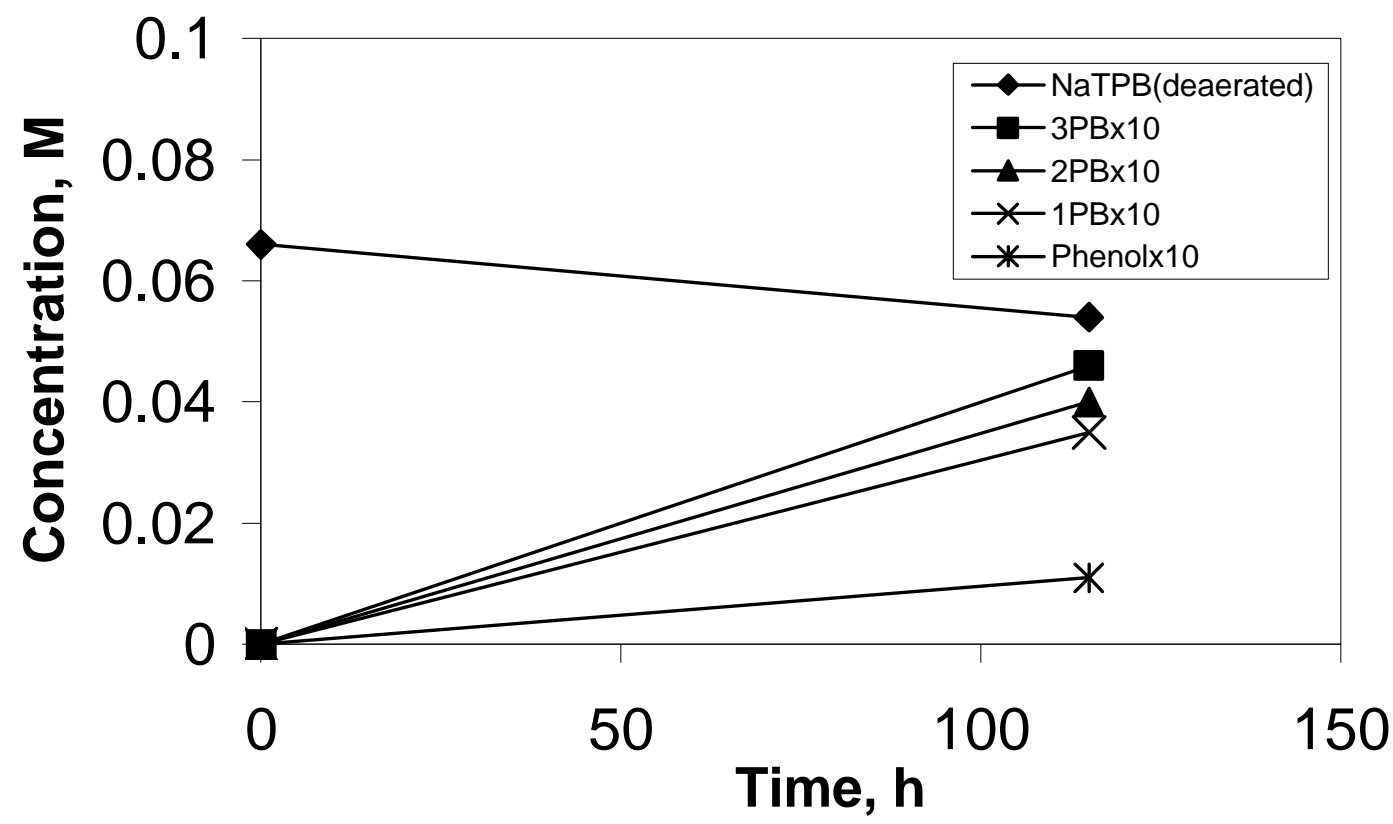


Figure $6(\mathrm{a}-\mathrm{c})$

Comparison of Measured Versus Predicted 3PB Decomposition
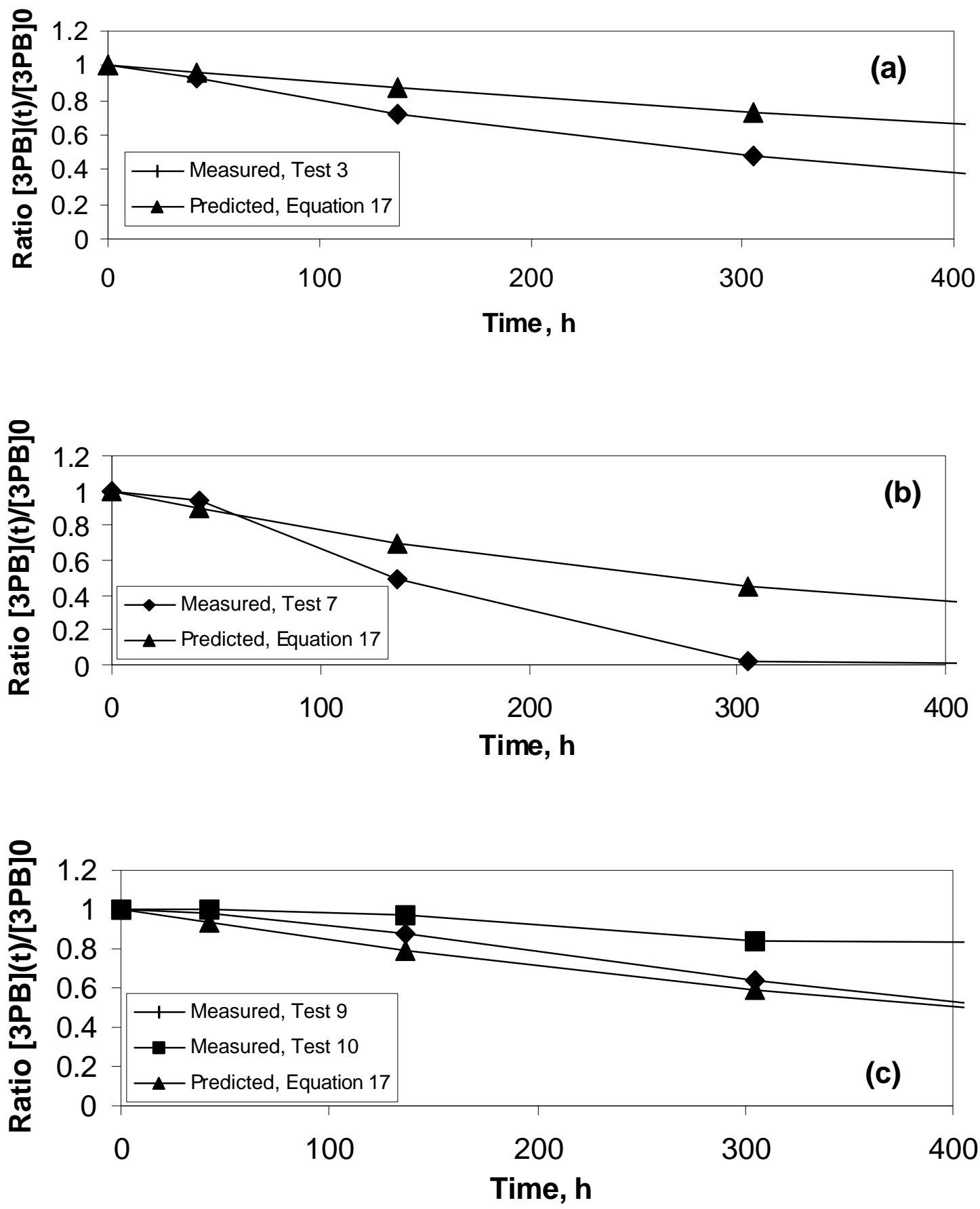
Figure 7 (a-c) Comparison of Measured Versus Predicted 2PB Decomposition
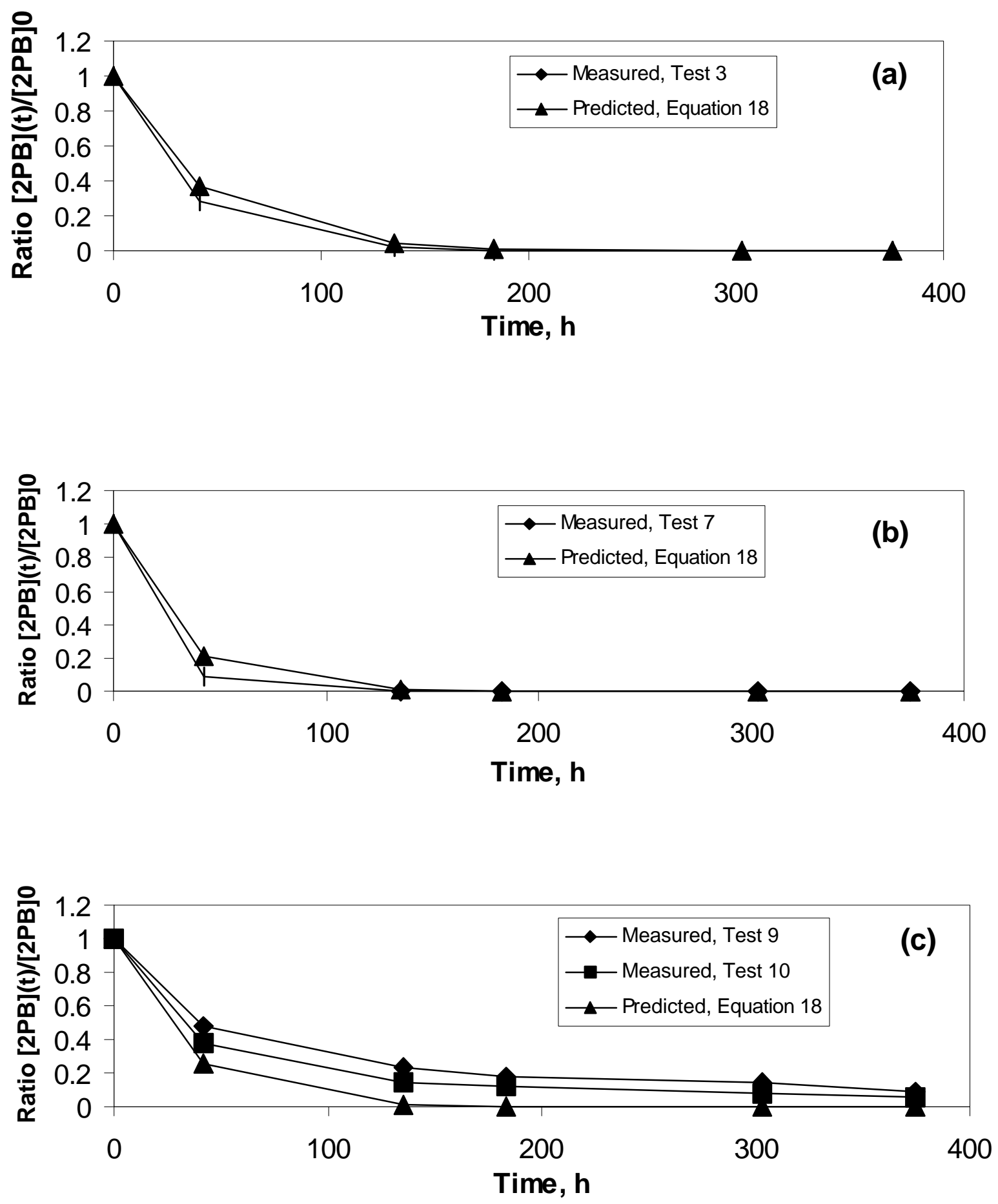
Figure 8 (a-c) Comparison of Measured Versus Predicted 1PB Decomposition
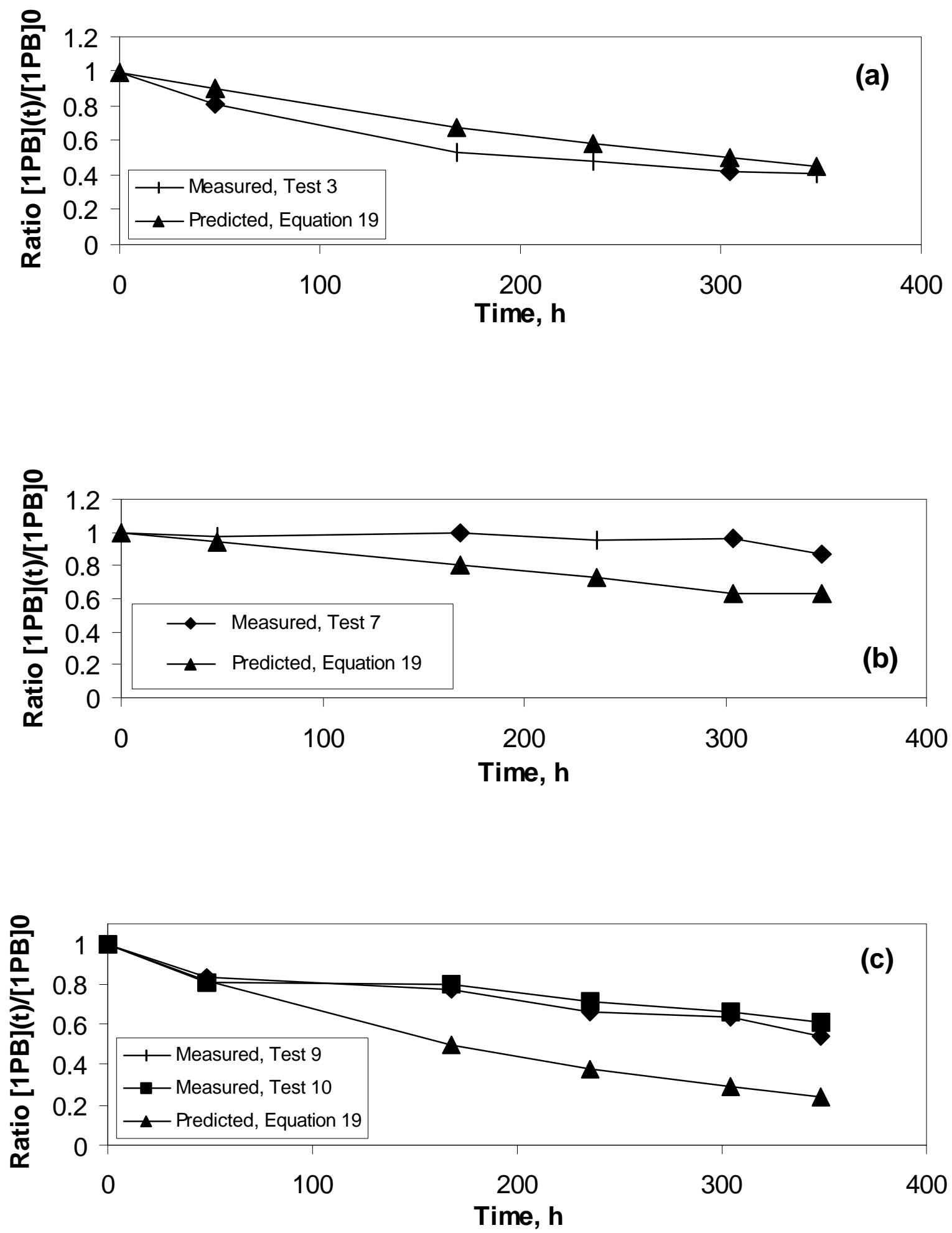
Figure 9 Arrhenius Plot of 2PB and 1PB Decomposition in Continuous Presence of Air

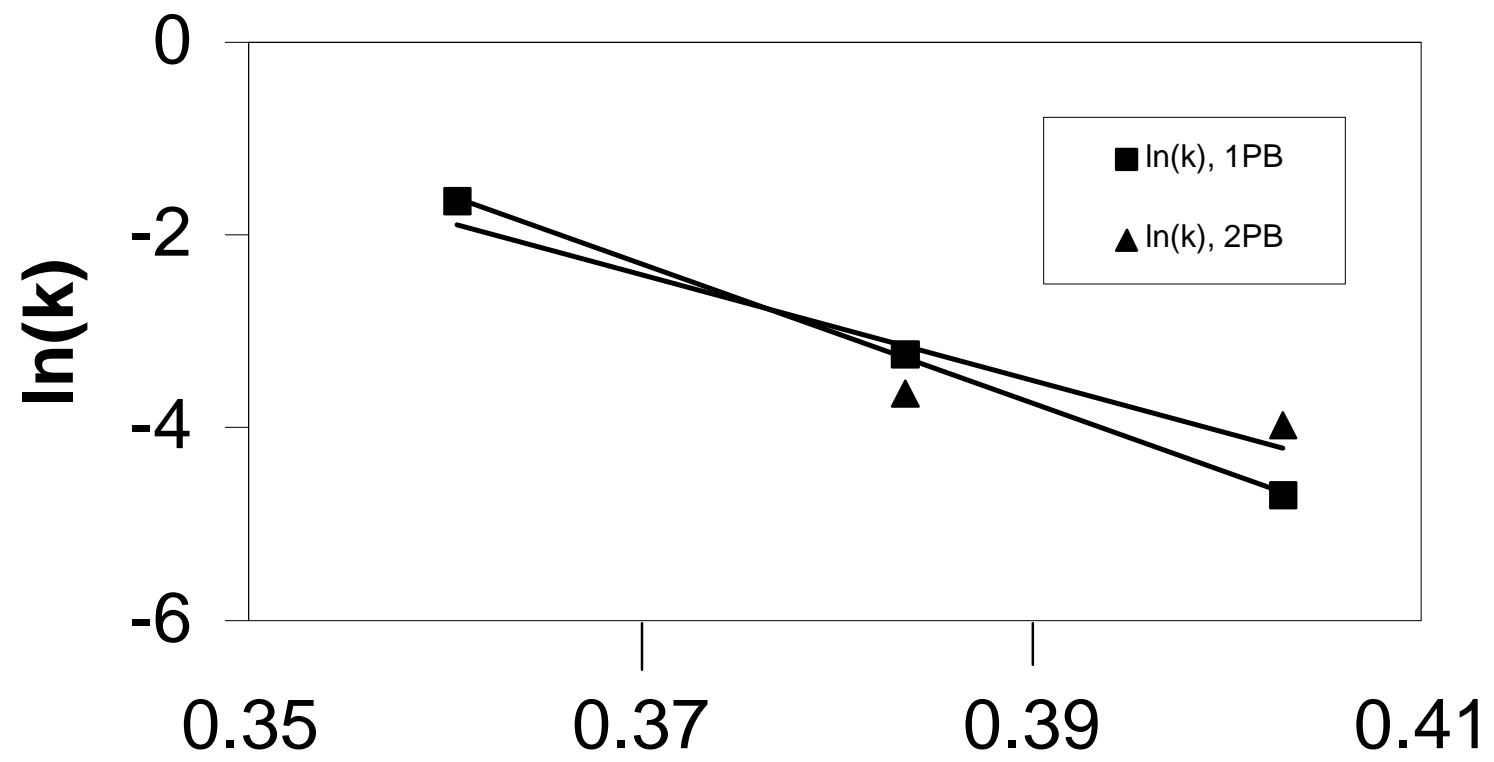

$(1 / R T) \times 1,000$ 